\title{
Hydrogen Peroxide for Power and Propulsion
}

\author{
by \\ Eur. Ing. P. R. STOKES, CEng, FIMechE, MRAeS \\ Read at the Science Museum, London on 14 January \\ 1998
}

\section{INTRODUCTION}

Germany, at war in 1940, accelerated the research and development it had directed through the 1930's to a new source of energy and its application. Applied earlier, it would probably have sustained Germany's early victories; by advancing technology in key areas, it might have changed the ultimate course of the war. This paper is concerned with the use of hydrogen peroxide at high strength, known in Britain as High Test Peroxide or HTP. Prime demonstrations of its potential are that in Autumn 1940 the German experimental Submarine $V 80$ attained an underwater speed of 28 knots compared with the 8 knots of conventional diesel-electric vessels and, in Autumn 1941, the Me 163a a rocket fighter flew at $624 \mathrm{mph}$ when contemporary advanced operational fighter aircraft sought to attain $400 \mathrm{mph}$.

The growth and application of the technology of hydrogen peroxide propulsion continued throughout the War. It was followed by withdrawal to the shadows of the international defence industry with an occasional public reminder of its potential. With its high specific power when utilised with fuels, balanced by an environmentally passive power used alone, its history and continuing potential as a future power source is a subject worthy of interest.

\section{HISTORICAL NOTE}

Hydrogen peroxide is present at low strength in the air, rain and, mildly concentrated, in ice. The laundress would gain a brilliant finish in her labours by outdoor drying finish on a frosty day. Peroxide was 'discovered' in 1818 by Louise Auguste Thenard. It was produced commercially with dilute acid acting upon sodium peroxide as 'soda bleach' where presence of sodium chloride was not objectionable. In 1873 Schering in Berlin substituted barium peroxide. In 1888 the process was applied internationally, Messrs. Laporte at Shipley in Yorkshire introducing it to Britain. These early commercial processes could only produce at low purity, limiting use to low concentrations since at high strengths impurities would catalyse it to an unstable condition. The demand for purity could only be met at that time by electrolysis. The principal application of peroxide was as a bleaching agent for more delicate fabrics 
such as silk \& wool and most notably straw and reed plait for the hatting industry; thus the plants at Warrington and Luton.

Improved methods of producing hydrogen peroxide were developed, especially in Germany, and in 1924 the process was further improved by the direct hydrolysis and distillation of the electrolysed solution of ammonium sulphate in sulphuric acid, the basis of modern manufacturing practice. Hydrogen peroxide was thus available in the 1930 s at $30 \%$ concentration for chemical and technological processes. It was used at 10 and 20 volume strengths for mouth-washes, disinfectants and 'blonding' of the hair. The 'volume' is the volume of the oxygen evolved by a given quantity of peroxide. Thus 10 volume produces 10 cc of oxygen gas for 1 cc of liquid. The $30 \%$ by weight product was produced as 'Perhydrol' in Britain and produces 100 volumes per cc. In the 1930's the first reference and patents appeared suggesting the possibility of power production from the 100 volume product.

Submarine ship history goes back to 1776 and various forms of propulsion were developed over the years. In 1896 the first power proposals to give an undetectable wake had appeared with a combination of steam storage and caustic soda re-activation on the 'Honigmann' principle. In 1901 the French patent of Dr. Jaubert had proposed a modified diesel engine cycle with a closed circuit, its exhaust scrubbed and enriched with oxygen. In 1905 the German Submarine Untersee No. 1 entered service with diesel and electric propulsion establishing the standard form of propulsion for the next 40 years through the two World Wars. From 1939 Germany placed particular emphasis on the requirement for speed with a single and versatile drive.

Powder rocket power is probably only pre-dated by the power of man, the animals, water and wind. The modem liquid fuelled and sustained chemical rocket dates from Dr. Goddard's project in the USA in 1926 using liquid oxygen and petrol, and the first rocket propelled aircraft was the Valier-Sander Rak 1 of 1929. It was flown by Fritz von Opel in Germany and had multiple solid powder rockets. The prime and parallel saga of rocket development, that of the $V 2$ and Space, is contemporary with this history of the application of hydrogen peroxide. ${ }^{2}$ The $V 2$ project was the subject of the recent paper to the Newcomen Society, 'The V2 Rocket: a Convergence of Technologies?', by John Becklake. (Transactions, Volume 67, 1995-96.)

\section{HYDROGEN PEROXIDE FOR POWER AND PROPULS ION}

Dr. Hellmuth Walter originated this work. Walter at age 30 was engaged as an engineer at the pioneering Germania Yard in Kiel, working on a gas turbine project to study ship propulsion light weight plant. Practical gas turbine work dates from 1894 in France by Armengaude and Lemale with their compact 500 hp unit, and in Germany with Stolze in 1900 at Berlin with his axial 'fire turbine'. ${ }^{3}$ While Walter subsequently pursued the peroxide solution, marine studies of the air breathing gas turbine continued through the war years in Germany with M.A.N, Blohm and Voss, and Bruckner \& Kanis, the latter with a gas-cum-steam cycle associated with their supply of turbines to Walter. Whilst these investigations led to the post-war developments in the light weight gas turbine for ship propulsion, the Walter peroxide turbine was the only one to enter service during the war. 
In his investigations, Walter recognised the particular problems of submarine propulsion with the need to share air/oxygen supply with personnel demands, so that the propulsion had to be a compromise: of diesel engines for surface sailing cruise and power generation, and under-sea operation at limited power with battery driven electric motors. Maximum contemporary submarine speeds were of the order of 20 knots on surface and 8 knots submerged. An interim solution alleviating this problem appears to have occurred to both Walter in Germany and a Lt. Cdr. J J. Wichers of the Royal Netherlands Navy, in 1933 proposals for use of an extendible air duct from the submerged submarine. The schnorkel, as it was called in German U boat service, had positive water exclusion valves allowing underwater power generation and operation.

With the gas turbine in submarines, its extravagant air requirement was ill-matched to availability. Having considered adding fuel to concentrated oxidant as a solution, Walter re-appraised the potential of both the diesel engine and the turbine. In studying concentrated oxidants he recognised that storage of oxygen posed problems of both high pressure and cryogenic handling. The alternative of nitric acid, with $63.5 \%$ by weight available as oxygen, had the disadvantages of its corrosive nature and handling problems.

Walter subsequently concentrated on the potential of hydrogen peroxide at high strength, recognising a duality of virtues in utilising both oxygen and steam as catalysed in continuous flow with pressure feed. A large volume of gas is produced with high heat of decomposition and at the then high strengths, nearly $50 \%$ of this would be oxygen with superheated steam at over $500^{\circ} \mathrm{C}$, enabling fuel to be burnt, thus further elevating the temperature and energy of the stream. This was an ideal energy flow for either turbine power, in a compromise between steam and gas turbine technology, or for rocket propulsion. Used by itself the temperature and energy of the gas stream is determined by strength of the hydrogen peroxide. Used with the combustion of fuel in the established stream, the temperature, varying with mixture ratio, can be moderated by diluting with water to increase mass flow. ${ }^{4}$

\section{THE PIONEERING PHASE}

Hellmuth Walter's early work was primarily directed to marine applications, although circumstances later broadened this to embrace involvement in rocket and other work. In 1933, from his working base at the Germania Yard, Walter communicated with the Electro-Chemical Works at Munich to request information and to enquire about the possibility of them supplying at least the $35 \%$ hydrogen peroxide thought to be available for specialist industrial use. The enquiry interested Albert Pietzsch, the founder of the firm and from this common interest, which was confirmed by the Naval High Command, research to produce progressively higher strengths was initiated. In October 1933, Walter jointly with the Germania Yard proposed a project to investigate the design of a high speed submarine, capable of achieving 30 knots submerged. With the interest of the Navy captured, in March 1934 Walter submitted a tender for a test steaming rig, including $\mathrm{CO}_{2}$ absorption to operate with $60 \%$ strength peroxide. Primary decomposition and combustion experiments were conducted in the grounds of the CPVA in Kiel-Dietrichsdorf in 1935, whilst work on a alternative closed circuit diesel concept reverted to a consultative capacity with the turbine now the favoured prime mover. 
In 1936 a report was submitted on practical operation of a 4000 hp turbine rig working on a 'Direct' system, that is, without an intermediate heat exchanger providing uncontaminated steam. This capitalised on the availability of hydrogen peroxide at a strength of $70 \%$, which extended the value of the heat of decomposition positively into the superheat range for the steam-oxygen mixture. This also ensured positive combustion of injected fuel for higher power levels. The trial also embraced jet condensing of the exhaust and re-compression, thus demonstrating development potential for the future. Hellmuth Walter was authorised to establish his own establishment, and leaving Germania Yard, this was initiated at Kiel Wik old Gasworks.

1936 was for Germany a momentous year for its military technology. It saw the creation of the Luftwaffe, the trials of the Me 109 fighter and the He 111 bomber, followed by the proving of the capability of Luftwaffe equipment consequent on deployment of the Condor Legion in Spain. The Siegfried Line was being built, the pocket battleship Deutschland and her sisters were at sea, and $U 28$, the first of the Type VII Standard Submarines was commissioned. The development of hydrogen peroxide power was now hastened. It received the cover name, 'Aurol' for ship propulsion, and would be dubbed 'T substance' (Stoff) for aircraft and missile applications, and 'Ingolin' for torpedo and artillery work. .

Walter commanded respect for the hydrodynamics of innovative submarine hull design, as well as for the acceptance of his hydrogen peroxide power plant. Following the 1934 project, design now proceeded on a small $2000 \mathrm{hp}$ turbine propelled experimental submarine. Displacing 76 tons and 22 metres in length, it accommodated a test crew of 4 . The engine was to operate, 'cold' utilising, 'Aurol' without the addition and combustion of fuel. Underwater speed was to approach an unprecedented 30 knots with a useful trials range of 50 miles. The construction contract was awarded at the beginning of 1939 to the Germania Yard, GW Kiel. ${ }^{5}$

Concerning rocket development, the comparative virtues of the use of hydrogen peroxide for rocket propulsion became a research subject for the Military, assessing the advantages of a number of possible oxidants. In 1934, the research branch of the Army Ordnance Department at Kummersdorf commenced trials with a 'Heylandt' rocket chamber, this a basic regeneratively cooled nozzle unit evolved in a former industrial partnership with Valier who had been killed in further pursuing experimentation with a rocket car. Another fatality now occurred when a trial was undertaken by a Dr. Wahmke in attempting to pre-mix hydrogen peroxide and alcohol upstream of the chamber. The intention had been use as a 'monergol' propellant, combining oxidant and fuel, but it resulted in a feed tank detonation. Similar experimentation with hydrazine hydride in the liquid phase was also set aside after 1936.

In the Autumn of 1936 Walter designed and built a 'T Substance' pressurised feed 336 lb. (150 kg) thrust rocket unit with $45 \mathrm{sec}$ endurance for use in flight trials, with the chamber filled with a paste permanganate catalyst before operation. This demonstrated the value of a conservative approach and the 'cold' rocket. The aircraft thus equipped was a He 72 Kadett, of a similar type to a British DH Tiger Moth. Two scenarios can be deduced from the information on this installation. The first indicates a scientific investigation into the early use as wing 'bonkers' in imposing a roll 
moment for aerodynamic stability study. The other is suggestive of a somewhat informal approach in supplementing thrust, thus aligning Walter with the enthusiasm of the members of the Berlin Raketenflugplatz of the VfR from which Von Braun and others had sprung. ${ }^{6}$

Flights then developed rapidly with a 300kg (660lb.) T Substance unit, designated $\mathrm{R}$ 1 , with the liquid catalyst Z Substance, permanganate solution. It had air pressure feed at a 20 to 1 ratio with an endurance of 30 secs. This was flown in a $F w 56$ Stosser aeroplane, which was a communications and aerobatic machine at the leading Research Establishment of the Luftwaffe, DVL. Its third flight was undertaken by Colonel Udet, who was both a sporting and professional service pilot, newly appointed as the Luftwaffe Head of Technical Development, and underlined its importance and interest. Parallel with this work, a Liquid Oxygen rocket engine for aircraft had been under development by Von Braun and encouraged by Ernst Heinkel as a secondary activity to Dornberger's artillery work at Kummersdorf, Berlin. There were, in effect, competitive trials of the two favoured oxidants, one dependent on hot operation, the other cold. They were now undertaken to boost the piston engined Heinkel He 112 fighter with a rocket power plant. In March 1937 it flew with the von Braun engine and in November with the Walter unit, evidently recognised by von Braun as of superior reliability. Trials with both engines were undertaken, boosting performance, and at take off with the primary power plant throttled back. With the Liquid oxygen (LOX) unit several fires occurred and an aircraft was written off, thus favouring the Walter rocket engine for manned aircraft.

The Walter engine as flown in the $\mathrm{He} 112$ was the first to incorporate controllable thrust with the utilisation of a steam driven turbopump for the T Substance. Maximum thrust was at $1000 \mathrm{~kg}$ (2000 lbs.), with endurance at this rating of $30 \mathrm{sec}$. Test flying continued from autumn 1938 at Peenemunde West and based on this success Ernst Heinkel designed and built, as a Private Venture, the diminutive He 176 rocket propelled aircraft with the aim of capturing the world speed record. The wingspan, with a symmetrical aerofoil, was $4 \mathrm{~m}$ with the wing area at $5 \mathrm{sqm}$. The pilot, Erich Warsitz, was an enthusiastic member of the team, sharing a desire to attain the magic $1000 \mathrm{~km} / \mathrm{hr}$, and would fly the aircraft in a recumbent position. It should be recollected that in 1939 international speed records were being intensively sought. Heinkel had held the speed record now broken in April 1939 by Fritz Wendel in a Me $109 \mathrm{R}$, with a Daimler Benz DB 601 at $2770 \mathrm{hp}$, at $755.1 \mathrm{~km} / \mathrm{hr}$ (469 mph); this was both technically and politically expedient since the Me 109 was Germany's committed first line fighter.

Rocket engine thrust for the He 176 was variable between 50 and $500 \mathrm{~kg}$ (110 and 1100 lbs.) in this application, with endurance limited to $60 \mathrm{sec}$ at full thrust. The engine was a self-contained unit with all-pneumatic control, so as to integrate with an airframe having a pressurised cockpit capsule, which allowed ejection in the event of major engine malfunction. This technology enabled Heinkel to introduce the first ejection seats. The aircraft flew from Peenemunde on 30 June 1939and was demonstrated with verve on 3 July to Hitler in the company of von Keitel, Jodl, Goering, Milch, Jeschonnek and Udet, with Heinkel also present. Although everyone was much impressed and Goering committed a cash bonus to Erich Warsitz, a service pilot, to be paid by Heinkel there appeared to be a feeling that the aircraft was too 
diminutive to gain proper regard. On 27 August 1939 the Heinkel He 178, the first gas turbine jet propelled aeroplane, flew. ${ }^{7}$

Flight trials with the He 176 continued intermittently with $500 \mathrm{mph}$ attained, but they ceased from September with the invasion of Poland and the subsequent state of war with Britain and France. The aeroplane was consigned to the Air Museum in Berlin and it was subsequently destroyed in the Allied bombing.

The pioneering phase can be judged as coming to its close.

\section{PEROXIDE POWER IN THE 1939-1945 WAR}

In April 1940 the experimental Walter submarine designated as V 80 commenced its trials in he Schlei Estuary off Kiel in the Baltic Sea. Hellmuth Walter was himself usually in charge with I crew of four including his test engineer Heinz Ullrich, who continued to be involved throughout he era of peroxide submarine development. Peroxide, now at $80 \%$ strength, was carried in plastic flexible tanks housed in a lower hull of the vessel. It was pumped from its underwater pressure, via a turbo pump as developed for the Heinkel aircraft, to the reaction chamber described as the Disintegrator' and operating at 35 atm. (515 psi).

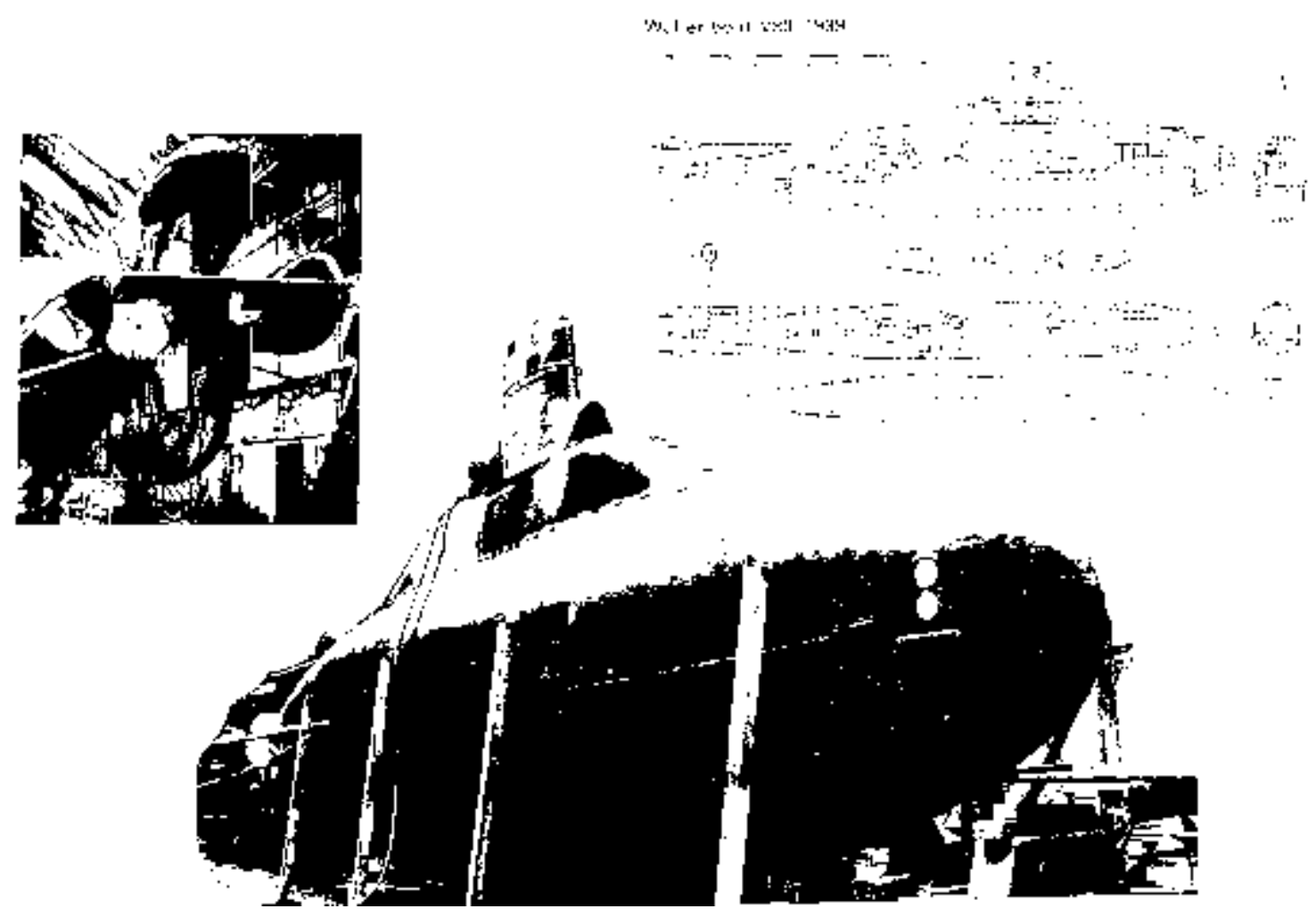

Fig. 1. The experimental Walter submarine V 80 under construction, including view of aft control surfaces, as portrayed in the Germania yard at Kiel in 1939. Courtesy Eberhard Roessler 'The U Boat', Arms and Armour Press

This unit and its ancillaries were a consistent feature of evolving practice. In both marine and other power applications, peroxide was catalysed and the resulting steamoxygen mixture was fed via a control valve to the turbine. Solid catalyst 'stones' were 
used, mounted in a meshed arrangement within a flow drum, with peroxide injected as a staged flow upstream. The steam-oxygen flow was emitted downstream via a residuals centrifugal separator described as the dust separator. This underlined the importance of erosion wear in high-speed turbine applications. Catalyst development was, and remained, a problem, platinum and silver although ideal were economically unattainable. At this stage the catalyst, coded as 'Z-substance' was permanganate as a liquid, or, in this case, coated onto porcelain stones and mixed with about 33\% copper coils in the steam generator. ${ }^{8}$

The turbine, by Bruckner \& Kanis, was a 2000 hp unit operating at 20,000 rpm via a 'Stoeckicht' planetary gearbox driving the crew at $1000 \mathrm{rpm}$. This was the first application of this epicyclic gearbox type with floating planetary gears, intended for a high-speed condition. Whilst the land test plant operating with combustion had recompressed the exhaust $\mathrm{CO}_{2}$, the turbine in $\mathrm{V} 80$ exhausted through the hull, so that only shallow diving depths could be explored. Despite this limitation, the V80 served as more than a straightforward engine test bed, as the hull and controls were designed to utilise the high underwater power and to explore speed potential, steering, dynamic submerging, surfacing and general sea keeping.

In the Autumn of 1940 the support facilities were transferred to deeper water within the security of the Baltic off Hela in the Gulf of Danzig and speeds were worked up over a total of 100 voyages to 28.1 knots. This unprecedented speed attainment with peroxide power, hull hydrodynamics and control design, created a deep impression within the secret world of U-boat technology and the German Naval High Command.

Germany entered the war with an advantage of highly developed military technology and, with Russia as its ally, this engendered a mood of invincibility. But that began to decline with failure in the Battle of Britain, Russia's stubborn resistance to attack in 1941 and the USA's entry into the war at the end of that year. The use of the technology of hydrogen peroxide power then became of increased significance in transition from blitzkrieg to a war of attrition and from attack to defence. Whilst developments proceeded in parallel, this narrative continues in chronological order, approximating to the benefit sought by Germany in sea, land and air warfare.

\section{SUBMARINE WARFARE}

Submarine warfare required the ability to operate submerged for long periods and to match the speed of surface ships. To provide this Walter worked with a combined team including the Submarine Department of the Supreme Naval Command and the Germania Works for the submission of a design, specified as $V$-300. This was to capitalise on experience with the V80. It was to be armed as a coastal submarine with six torpedoes. A contract was obtained in February 1942 for construction as U791 to the new high speed hydrodynamic form with a single screw power plant geared to twin shafts, each driven by a combination of $2000 \mathrm{hp}$ peroxide/fuel 'hot' turbine to the full condensing and exhaust system, supplemented by a $150 \mathrm{hp}$ diesel, and a $75 \mathrm{hp}$ slow speed electric drive providing maximum speed, cruise and loiter. Displacement was at 655 tons, speed underwater up to 20 knots and manned with a crew of 25. 
As could be expected, with the introduction of new technology to traditional Naval Construction integrated with its supply industry, an immediate variation occurred. The single prototype design was changed to twin source, extending the technology and competition and capitalising upon established experience, a situation similar to the UK set-up with Whittle's pioneer Power-Jets organisation. In addition, the range of the craft was increased to that for practical operation in the British approach waters. The Walter peroxide turbines were uprated to $2500 \mathrm{hp}$ to give the vessel $5000 \mathrm{hp}$ and an increased speed potential. In addition there were $210 \mathrm{hp}$ diesels while the electric loiter drive was a single $77 \mathrm{hp}$ unit. Germania Works would develop a design reflecting their constructional practices as WK 202, and Blohm \& Voss were brought in for a competing design Wa 201. Proposed hull lines for both were tank tested at Hamburg, and their control systems at the Brunswick Aviation Research establishment.

In summer 1942 prototype contracts were placed as U792 and U793 with Blohm \& Voss, and for U794 and U795 with Germania Works. Construction followed with some refinement of design difference consequent on the research findings. Such was the confidence of Supreme Naval Command, backed by Hitler at a Reichs Chancellery conference in September 1942 attended by Keitel, Räder and Dönitz, that in January 1943, with Admiral Dönitz now Supreme Commander-in-Chief of the Navy, further orders were placed for the Blohm \& Voss boats as Type XVIIB, U 140516, and from Germania Yard as XVIIG, U1081-1092. In May 1943 the 'hot', fuel injected, peroxide power plant commenced testing with a dockside test bed simulating Wa 201, initially with a steam supply from a battery of conventional Henschel high pressure boilers. In September 1943 U792 was afloat at Blohm \& Voss and in October U794 at Germania Works. Initial trials were undertaken at low speeds utilising the electric drive backed by the diesel engines battery charging. U792 continued as the lead vessel and the first trials with the peroxide system were undertaken from December 1943 both on surface and submerged. They were somewhat inhibited by turbine labyrinth steam leakage into the engine compartment. Further problems were due to poor peroxide concentration and a mild explosion in the combustion chamber. On coming to dock following this incident, the vessel collided with the jetty. 


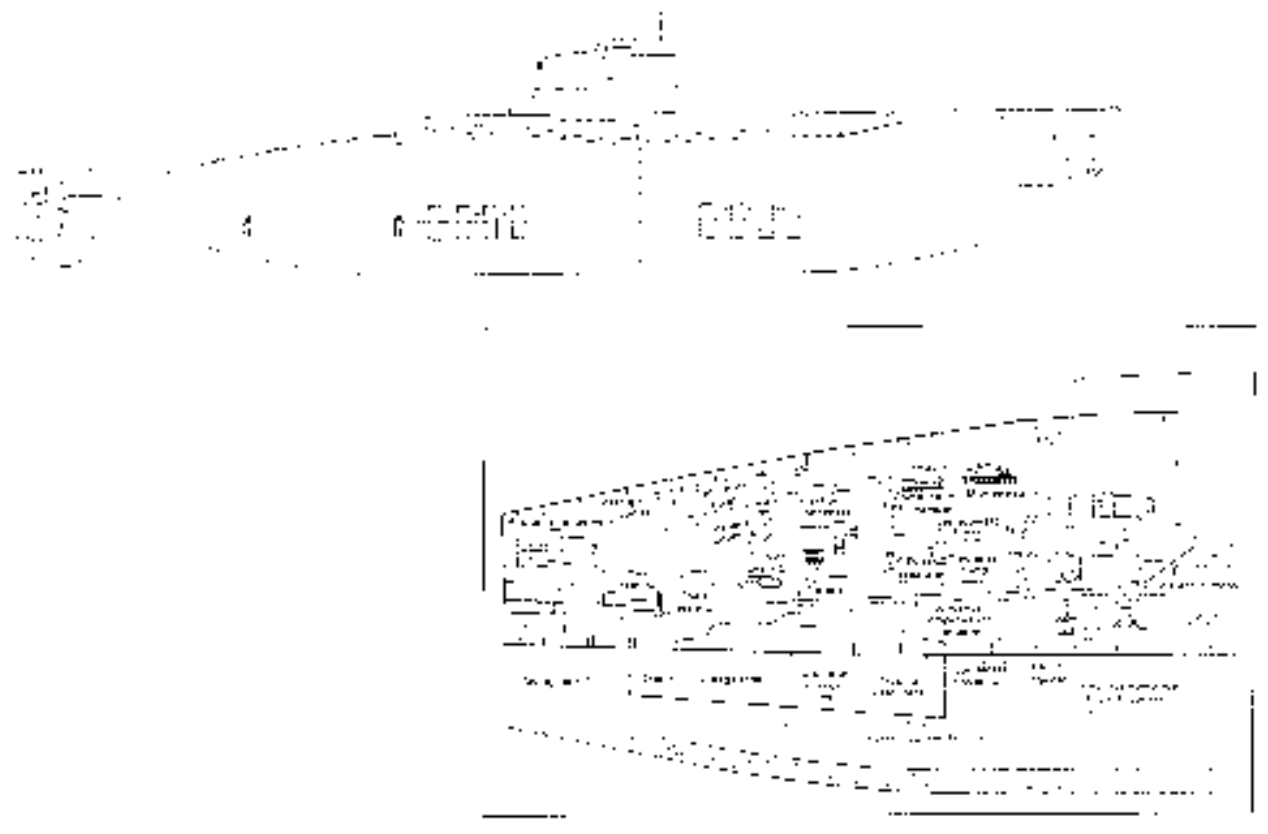

Fig. 2. Profile and the peroxide turbine compartment, of Type XVII Submarine. Note surface diesel engine and 'loiter' electric drive forward in hull. Peroxide catalysed in 'Disintegrator', fuel and water coolant to 'Combustion Chamber' and output via 'Dust Separator' to Turbine. Discharge via Injection condenser to hull surface condenser. Note also high speed 'Stoeckicht' gearbox in propeller drive. Courtesy Eberhard Roessler The U Boat. Arms and Armour Press

In a February 1944 voyage, 50 minutes of continuous underwater operation of the Walter system was achieved and, at the end of March, with clearance of the teething troubles, Dönitz visited and took part in a sea trial of U794 demonstrating repeated changeovers from peroxide to electric drive. This participation by Dönitz, together with four other Admirals of his entourage, is suggested as the only occasion on which five Admirals had been at sea together in a single submarine and was a remarkable demonstration of confidence in the Walter technology. Development continued with these first boats. They were joined by others of the class through 1944, and were given approval by the $U$ Boat Acceptance Commission in the October with transfer to the training units and worked up for service as the new class.

From the September 1942 meeting, another programme was launched with enthusiastic endorsement by Dönitz, who was investigating an Atlantic submarine. This was first specified in October 1942 as Type XVIII a Walter twin screw design with two 6000 hp turbines introducing exhaust gas compression, together with 2000 hp diesels with 200 hp electric drive. After considerable commitment to prototype construction, the design was superseded in May 1944 by Type XXVIW with a single screw, 7500 hp turbine and 600 hp diesel, and the construction of this was initiated for planned launch by March 1945.

Complementing the major submarine endeavours was a Torpedo development programme utilising Walter turbine technology, G7ut 'Steinbarsch', etc, progressing through a number of variants at $4001430 \mathrm{hp}$ and 45 knots. That suggested a power unit using both fuel and water injection. In addition there were two peroxide jet 
propelled air launched torpedoes, LT 1200 with lift wings shed on water impact, and from 1941 the LT 1500 design to be dropped in the conventional manner with propulsion initiated underwater. LT 1500 utilised a thrust of $800 \mathrm{~kg}$ with an underwater speed at 40 knots and range of 2000 metres with a $300 \mathrm{~kg}$ warhead, but no record is suggested of its entry to service. In 1945 another project under construction as a Walter initiative was the Type $X X V I I F 2$, 'Schwertal', a two man submarine to be 'flown' under water and powered by a water injected Walter peroxide turbine. ${ }^{9}$

\section{GROUND BASED MISSILE OPERATIONS}

In the field of long range ground launched military weapons, the major programme initially was for the A4 liquid oxygen-alcohol rocket missile on which design proceeded from 1940 on the basis of prior experimentation with an A3 half scale unit similarly powered. In the period 1938-1939 specific aerodynamic and control system research for this programme and for a similarly configured anti-aircraft proposal, had been undertaken with a unit designated AS. In investigating profile and tail fin configuration, some fifty scale units were powered by Walter $120 \mathrm{~kg}$ (145 lb.) peroxide with paste catalyst rocket motors. The major peroxide involvement in the ground based missile field resolved as two programmes for key ancillaries, the turbopump system for the A4/V2 rocket missile developed by Army Ordnance at Peenemunde East, and the catapult launching system for the Fiesler FZG 76/V1 Flying Bomb developed from 1942 at Peenemunde West by the Luftwaffe. ${ }^{10}$

Considering the $A 4 / V 2$, a fundamental problem, primarily of weight, in $A 3$ and $A 5$ was the utilisation of tank pressurisation to generate chamber pressure. The $V 2$ was rendered practical by the application of the peroxide turbo-pump.

Fig. 3- The peroxide system and $675 \mathrm{hp}$ turbo pump for the A4IVZ Rocket missile rendered it practical as long range missile in allowing the flow of its liquid oxygen and alcohol main propellants from tanks to the rocket chamber at 300 psi. Courtesy, Institution of Mechanical Engineers (Meeting 121945 introduced by W G. A. Perring)

The propellant feed of liquid oxygen and alcohol was by centrifugal co-axial, central, single stage, impulse turbine driven by decomposed peroxide with instance of a liquid catalyst. The $18.5 \mathrm{in}$ turbine developed $675 \mathrm{hp}$ at $5000 \mathrm{rpm}$ from $3.7 \mathrm{lbs} . / \mathrm{sec}$ and 300 psi. Pump impellers were conventional, in derivation from fire pump practice, in a single stage delivering at 370 psi $65 \mathrm{lbs}$./sec of oxygen and $110 \mathrm{lbs}$./sec alcohol. To suppress cavitation on the pump inlets ram air pressure was applied to the alcohol tank and a small proportion of pumped liquid oxygen was bled through a turbine exhaust heat exchanger to pressurise oxygen tank. ${ }^{11}$ No serious peroxide related problems were reported during the development of the $V 2$; this was aided by a routine of production clearance running on test facilities for pump under refrigerated conditions. Considering the work associated with the $V 1$, it has both straightforward and partially obscured relationship with the Walter organisation. The resonant duct principle by the engineer Paul Schmidt through the 1930s, at which period Walter had ramjets and a rocket/ramjet. In March 1942 the Flying Bomb was proposed by Fiesler Aircraft of Kassel. Gaining acceptance and designated as the Fe 103, it was to be powered by Messrs. Argus with a resonant duct engine developed from the Schmidt design. Whilst the evolution of the project had come under Army control, acquiring an Artillery designation as FZG 76, was transferred to the Luftwaffe with a probable intention of capitalising on rivalry. In 1942 it was tested in an air launch from 
Peenemunde West and then catapult launched for the time. Its pulse jet engine depended on ram air for compression, this enhanced by resonance with entry reed valves. It had to be started at flying speed, and a ground launch catapult arrangement was energised by peroxide.

The unit moved on a carriage mounted on a target aligned ramp housing an extended cylinder with a steam driven piston in the manner of the atmospheric railway, with 'steam' supplied by decomposed peroxide. Ingenuity was required to regulate both the pressure and the volume of the propellant during acceleration of the missile to flight speed. This involved pressurising the feed tanks and varying the length of the fluid feed pipes for both the peroxide and permanganate catalyst to four phased injection heads. Walter quoted as an achievement the rate of $143 \mathrm{lbs}$. of peroxide decomposed progressively in 0.5 seconds for the launch. The flying bomb assault on London was launched on the morning of 13th June 1944, followed by that of V2 on the 8th September. It is of interest that, until the eve of this assault, Allied intelligence had considered that both the $V 1$ and $V 2$ used hydrogen peroxide as their primary power source.

Interesting asides arise. Firstly that the principle and development of the peroxide catapult system may have been extended to the stillborn V3 'London Gun', a large edition of the various steam guns proposed in the past. Referring specifically to the use of peroxide as 'Ingolene' in guns, a 1945 Intelligence report commends the ability to achieve a constant pressure along a gun barrel and cites satisfactory results with a $15 \mathrm{~cm}$ mortar, 'P-Werfer' giving a 2000 metre range 'Silent and invisible at night, though by day a cloud of steam could be observed.'

The report continues that in applying the principle to a long range gun as a primary requirement of research, it was found that the uniformity of pressure obtainable was limited by the rate of gas transmission.

The difficulty could be overcome by feeding in gas progressively at a number of points along the barrel. The same principle could of course be adopted with an explosive charge, but an advantage of using ingolene is that a single combustion chamber could be used, the gas being supplied to the various feed points through pipes. This multi-stage system was never used in practice. ${ }^{12}$

A further point, revealed by the same report, suggests that the Walter research group played a more significant part in the development of the pulse jet and ram jet than had been appreciated. In considering overall work on propulsive ducts undertaken from 1936 to 1945, one of those interviewed post-war at the Walter Works was a Dr. Schmidt, in charge of development. A test plant had been operated adjacent to Kiel power station, absorbing $800 \mathrm{~kW}$ with a compressor delivering $17 \mathrm{lbs} . / \mathrm{sec}$ at 6 atmos for a supersonic stream at atmospheric pressure for models to 6.9" diameter. Testing had been undertaken for a range of ramjet configurations, L-motor (Lorin propulsive duct), RL-motor (Rocket Lorin), LR-motor (Lorin Rocket) with peroxide rocket downstream, and TLR (Turbine-Luft-Rocket) with air compressor driven by a peroxide turbine. In addition it was intended to develop an intermittent jet action like the flying bomb duct, adapted to a turbine drive in the manner of an explosion turbine and applied to underwater propulsion. Regarding anti-aircraft missiles, a number, including 'Enzian', were peroxide powered in development. However General 
Dornberger stated that by 1942 Peenemunde had been faced with many different submissions for anti-aircraft missiles and these were then rationalised to three using 'Salbie' or Nitric Acid.

\section{AIRCRAFT PROPULSION}

Dr Alexander Lippisch was the aerodynamicist who pursued to a successful conclusion the concept of the tailless aircraft and the Delta configuration. He had also been advisor for a brief flight of a rocket assisted canard glider over a mile in 1928. He pursued his work at the German Research Institute for Glider Flying, DFS, for high speed trials on the Delta configuration with the Walter $R 1$ cold rocket motor evolved for the He 112 and $\mathrm{He} 176$.

At the end of 1938 the small Lippisch design organisation was incorporated, as 'Department L', into Messerschmitt at Ausburg at the behest of the Ministry of Aviation, RLM. In 1940 the DFS 194 was first tested air-towed. In the summer it was tested with its rocket unit, limited by pump cavitation to about $400 \mathrm{~kg}$ thrust and $350 \mathrm{~km} / \mathrm{hr}$. Transfer from tankage to engine of high oxidant flow rates was to persist as a problem of rocket technology.

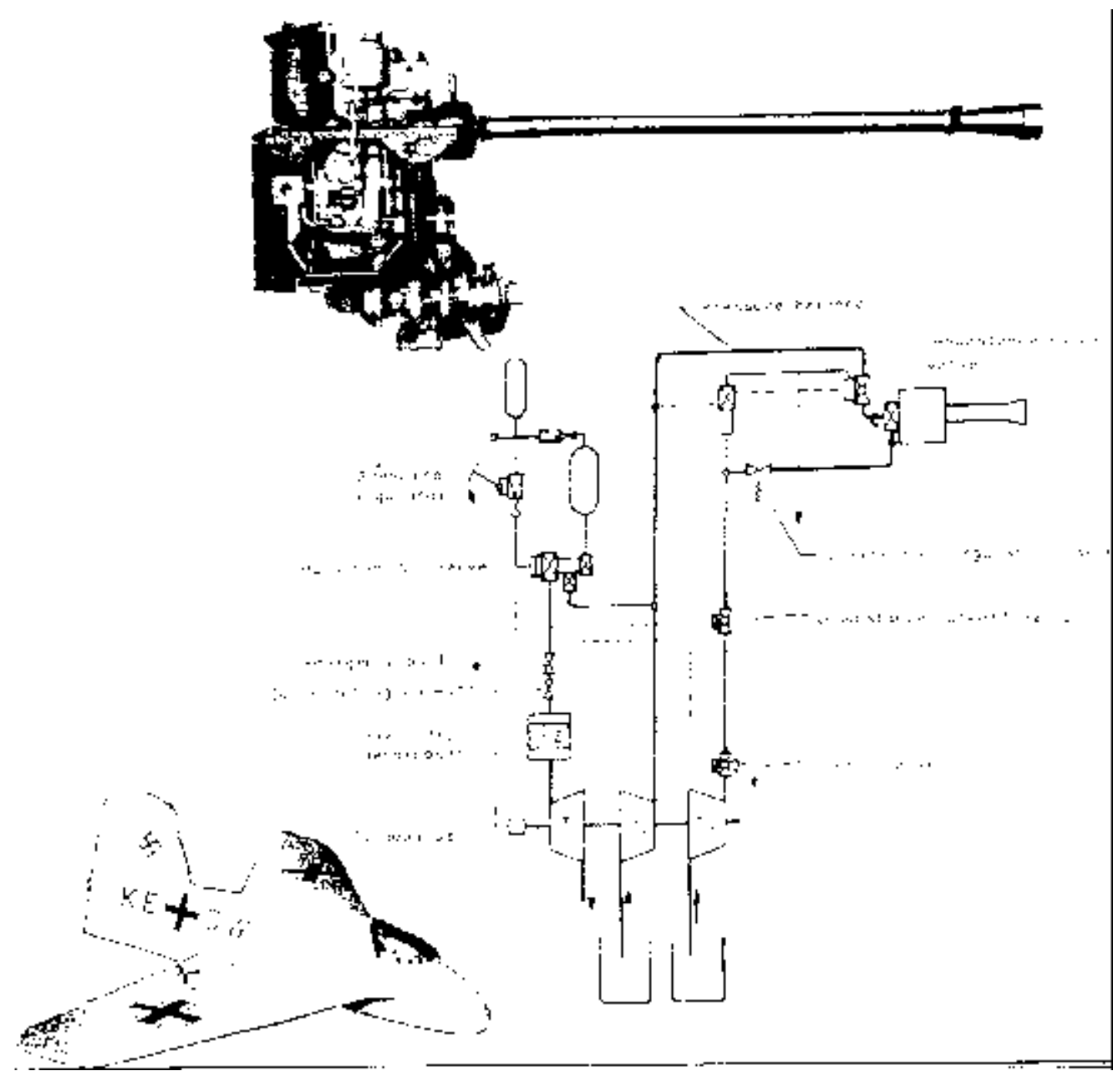


Fig. 4. The Walter Rll 203 'cold' rocket motor with its propellant system and turbo pump as representing the first installations in the DFS 194 and Me 163a as flown in 1940141. Courtesy, Department of Documents, Imperial War Museum

Construction arrangements were then made for the Me 163 interceptor fighter in an initial experimental batch of 16 for training purposes in introducing the new technology to the Luftwaffe. Competition for the power plant emerged with proposals from BMW with the 'Salbie' nitric acid oxidant, but the Walter peroxide engine was selected. As developed with a thrust variable between 150 to $750 \mathrm{Kg}$ (330 to 1650 lbs.) it was flight accepted at Kiel in July 1941. The Me 163a V4 then flew on 13 August 1941.

In this engine configuration, the T Substance (peroxide) turbo-pump now drove both the main peroxide pump and another pumping the liquid catalyst to the rocket chamber. Development aspects reported were that the peroxide was now at $80 \%$ strength, and the liquid catalyst was sodium permanganate, Z Stoff $\mathrm{N}$ for summer operation and Z Stoff C, calcium permanganate, for winter operation dependent on freezing point.

A Peenemunde contribution is noted in pride expressed by their Chemistry department related to a solution, with this installation, of a universal problem with solid catalysts as used for steam generation in the various turbine turbo-pump variants developed by the Walter Works. With repeated use, the catalyst, impregnated manganese cement porcelain pellets combined with copper coils in a caged flow chamber, crumbled with consequent residuals clogging filters and valves, etc. This had become a notorious problem now solved by the evolution of porous pellets with added table salt washed out after process firing. This innovation read across to other programmes inclusive of the Submarine's and V1 launch, etc.

On 2 October 1941 with an air tow to 10,000 ft to maximise propellant availability, in a straight and level flight the prototype Me 163a aircraft achieved $1000 \mathrm{kph}$ (624 $\mathrm{mph}$ ) on a theodolite checked course, a prime and emotive datum speed in metric terms still elusive in the jet fighters in the immediate post war world record flights. ${ }^{13}$

Other developments related to assisted take off (ATO) units made an immediate contribution to Luftwaffe capability from 1939. These were initiated by a prototype 'cold' unit that could be jettisoned, the RI 200 developed from 1937 at $500 \mathrm{Kg}$ (1100 lbs.) thrust over 30 seconds. Demonstration by a Heinkel He 111 bomber with these ATO units was regarded as the major event in the display to Hitler and his Chiefs of Staff in 1939 when the He 176 made its brief appearance. As the RI 202, this unit was put into mass production by Heinkel in a programme for 6000 units, a very positive boost for Hellmuth Walter, although this quantity was found to represent excessive production. A similar airborne missile unit, air pressure fed with peroxide and catalyst, and controlled by electrically rupturing feed bursting discs for $600 \mathrm{Kg}$ (1320 lbs.) thrust over 10 seconds, was that evolved for the Henschel Hs 293 glide-bomb as the first rocket weapon to assault the British Navy, initially in ship strikes in the Mediterranean including the loss of HMS Egret in August 1943. 


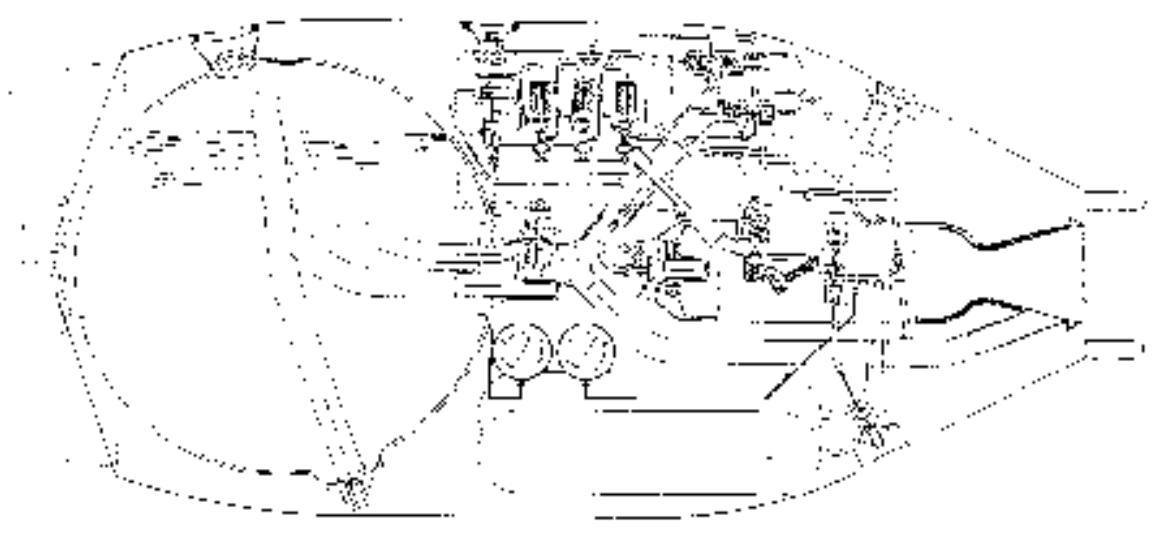

Fig. 5. The simple RI 2021109-501 Assisted Take Off, ATO, 'cold' rocket motor with hydrogen peroxide in its spherical tank, and calcium permanganate in the small cylindrical tank obscured by sequence valves. Gas pressurised to provide $500 \mathrm{~kg}$ (1100 lbs.) thrust for 30 seconds. Operating in pairs to assist bomber take-off, and then parachute dropped for recovery, they were in service from 1939 with 6000 produced by Heinkel as the first routine use of liquid propellants. Courtesy, Department of Documents, Imperial War Museum.

The first 'Hot' peroxide rocket engines evolved with the relatively simple ATO units, these being developed to higher thrusts with fuel addition doubling 'impulse', the product of thrust and time, at a similar weight. The RI 203 and RI 209 types added to the pressurised tank feed of peroxide and catalyst a third feed of petrol, dosed with hydrazine hydrate, for combustion. Exhaust temperature rose from the $600^{\circ} \mathrm{C}$ of the cold unit to the order of $1900^{\circ} \mathrm{C}$, introducing the need for nozzle throat cooling. This was simply achieved by circulation of the peroxide through a cooling jacket in transit to the reaction chamber. The two units were for $1000 \mathrm{~kg}$ (2200 lbs.) or $1500 \mathrm{~kg}$ (3300 lbs.) sustained for 42 or 30 seconds dependent on the size of metering orifices. Flight tests associated with the four engined He 177 bomber were undertaken from the end of 1941 although the project was cancelled in 1942 after development problems with this aircraft.

The fully operational variant of the Messerschmitt fighter was to be the $M e 163 \mathrm{~b}$, authorised in Autumn 1941 with a contract for 70 aircraft, the first batch at 26 scheduled for delivery by September 1942. Engine design was now required to double thrust for the fully armed and equipped interceptor, this of course recognising that it could be achieved in running the engine hot, the norm for a rocket engine, with attendant benefits of the potential halving of specific propellant consumption and improvement in the range of the aircraft. The ability to apply peroxide to the turbopump and as a monopropellant 'cold' for part of the power envelope was a unique attribute in competition with the alternative of liquid oxygen or nitric acid. ${ }^{14}$

The new engine was derived from the combination of previous practice on the RII 203 power plant of the Me 163a and the RI 203 'Hot' ATO unit. Use of the three liquid system utilised in the ATO unit would be impractical in the pumped sustained unit, so a combination of fuel and catalyst was devised in a research programme at the Rocket Section of the Air Ministry, LFA at Volkenrode. This was with C-Substance comprising a mixture of methyl alcohol and hydrazine hydrate with copper salts 
added as catalyst. Development proved difficult. With injection of peroxide and the C-Stoff, combustion over the planned thrust range was not achieved, although this was partially corrected with a primary flow to a pre-combustion chamber. Peroxide cooling of the chamber was found to be inadequate. Two stages of turbo-pumping were committed having individual turbines, the first low speed to obviate cavitation and tank pressurisation requirements, and to boost the second high speed delivery pump in series. A satisfactory control system that could be throttled could not apparently be attained.

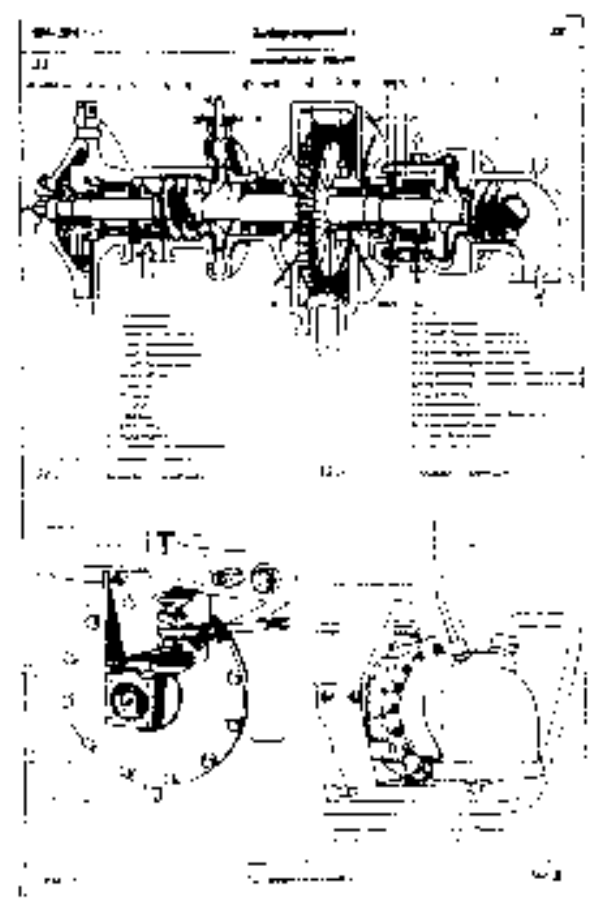

Complete redesign was undertaken in 1942 as the RII 211. A new turbo-pump was designed by Bruckner \& Kanis, the turbine supplier for the Submarine work and with particular attention to inlet flows utilising a screw booster it achieved altitude performance in a single stage. The combustion chamber was redesigned with cooling by the C-Stoff flow and with propellant injection progressive over three nozzle stages. With this a mechanical throttle control was achieved with two interrelated units, one controlling the progressive stages of injection and the other relating turbine speed/flow to thrust/chamber pressure. Development now became relatively straightforward with initial flight approval gained in May 1943 at Type 109-509, Mark A. Rating was at a maximum thrust at $1500 \mathrm{~kg}$ (3300 lbs.), minimum thrust 150 $\mathrm{kg}$ (330 lbs.), specific consumption, at sea level maximum thrust $5.7 \mathrm{~kg}$. sec and dry weight at $170 \mathrm{~kg} .15$

Fig. 6. The peroxide/steam driven turbo pump for pumping the peroxide oxidant and catalyst/fuel as representative of the enabling technology applicable to both submarine and aircraft development- The unit shown is that for the Walter 109-509 rocket unit in its developed form, with screw boosters to alleviate cavitation in altitude manoeuvre. Courtesy Department of Documents Imperial War Museum

The first Me $163 \mathrm{~b}$ had been flight tested without an engine as a ballasted airframe on 26 June 1942, released from air tow with a Me 110 aircraft. Now the first flight of the 
Me 163b VA-SS, Production No V 21, 'hot' with its 109-509A engine took place on 24 June 1943 from Peenemunde. There was thus a year's delay, mainly due to engine development problems and the need for major re-design. It is intriguing to compare this with the first British jet fighter, the Gloster Meteor. Grounded after its taxiing test in September 1942 it awaited its planned flightworthy engine until June 1943, although it flew in March 1943 with a DH engine. The parallel might have been closer in that with delays, plans were again considered whether to use a BMW nitric acid engine, although this too was suffering development problems.

Production of the Me $163 \mathrm{~b}$ was now established after flight development work, with the engine as the 109-509 AZ with maximum thrust raised to $1700 \mathrm{~kg}$ (3740 lbs.). The work included the introduction of a steam ejector arrangement removing vapour collecting at the pump inlets. This resolved the former persistent problem in manoeuvring at altitude. Also the introduction of gravity fed self-pressurising peroxide starting to the turbine eliminated electrical requirements. Some 300 engines at this standard were built.

Two aircraft were demonstrated at a major Luftwaffe display for new aircraft on July 24th 1943, and it was introduced to service progressively through a newly formed Test Detachment 16 with combat experienced pilots under training from August 1943. Group Jagdgeschwader 400 operated from June 1944, planned for tactical operation from 12 suitably equipped defence air fields serving critical targets, and in August 1944 the first combat success was achieved in the destruction of an American B 17 Bomber. The psychological effect on Allied day bomber crews was considerable with attacking passes through the formations at speeds approaching $600 \mathrm{mph}$. Operations with the Me 163 however only resulted in the destruction of some further 12 Allied bombing aircraft. 


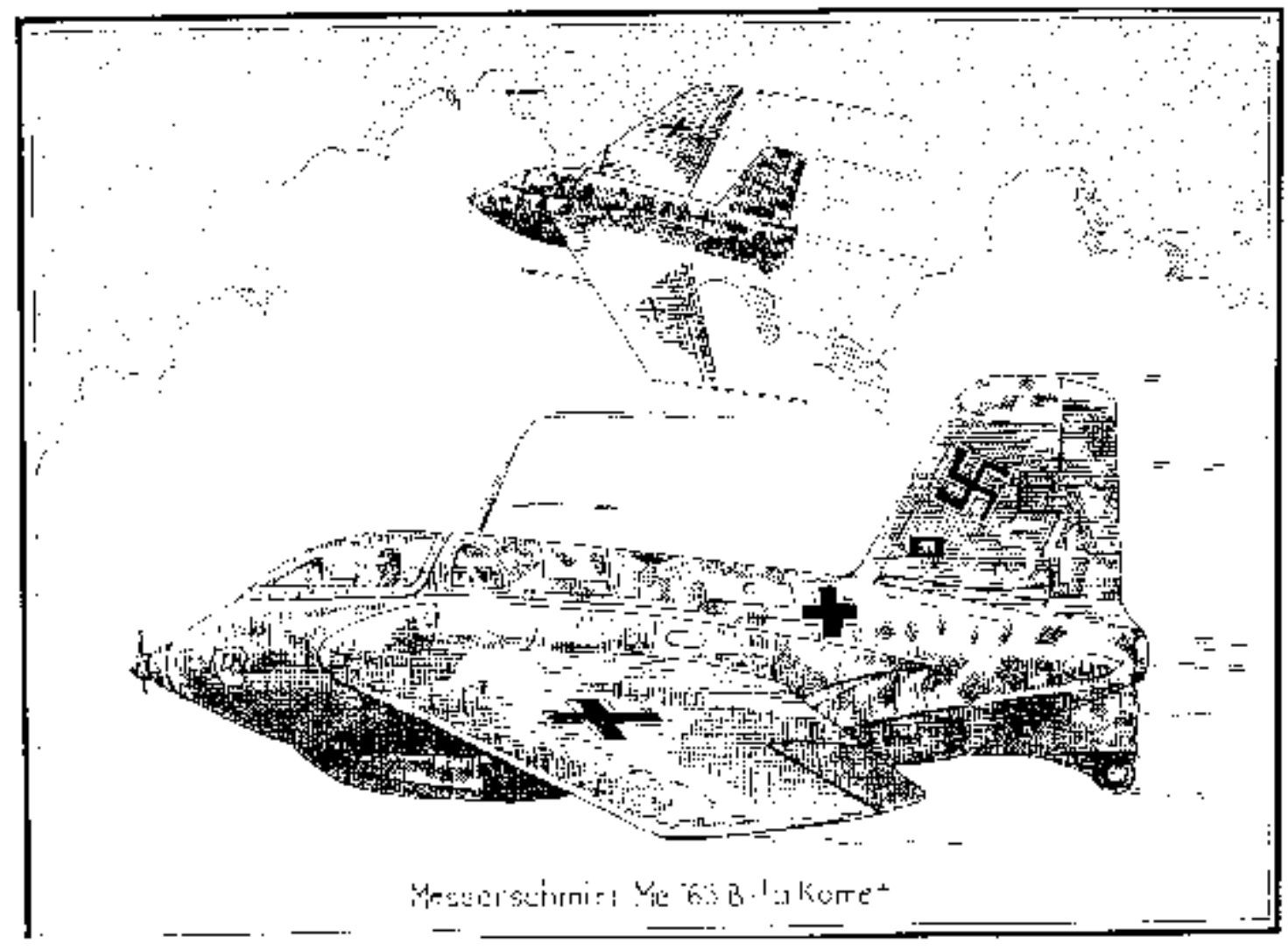

Fig. 7. Operational Me 163 interceptors of 1944 with Walter 109-509A-l Rocket Motors. Operational were to Mach 0.8, problems occurring from 0.84 with nose down pitching. A speed at $1130 \mathrm{~km} / \mathrm{hr}$ (700 $\mathrm{mph}$ ) was claimed at medium altitude in experimental flying in June 1944. Sketch, Courtesy Bob Tanner RRHT Rolls Royce Heritage Trust

With Japan in alliance with Germany, production of high strength hydrogen peroxide initiated in early 1944 with Mitsubushi Seishi Kaisha for use with an Me 163 type aeroplane Shusui, and a further advance in their sophisticated torpedo technology with Kaiten. The Yoko Suza Company was to produce the Walter 109-509b engine. Japanese communication with Germany had a high dependence on submarine transportation and, with material consignments lost in 1944, only one prototype powered flight was achieved, that in July 1945 with a pilot fatality. 


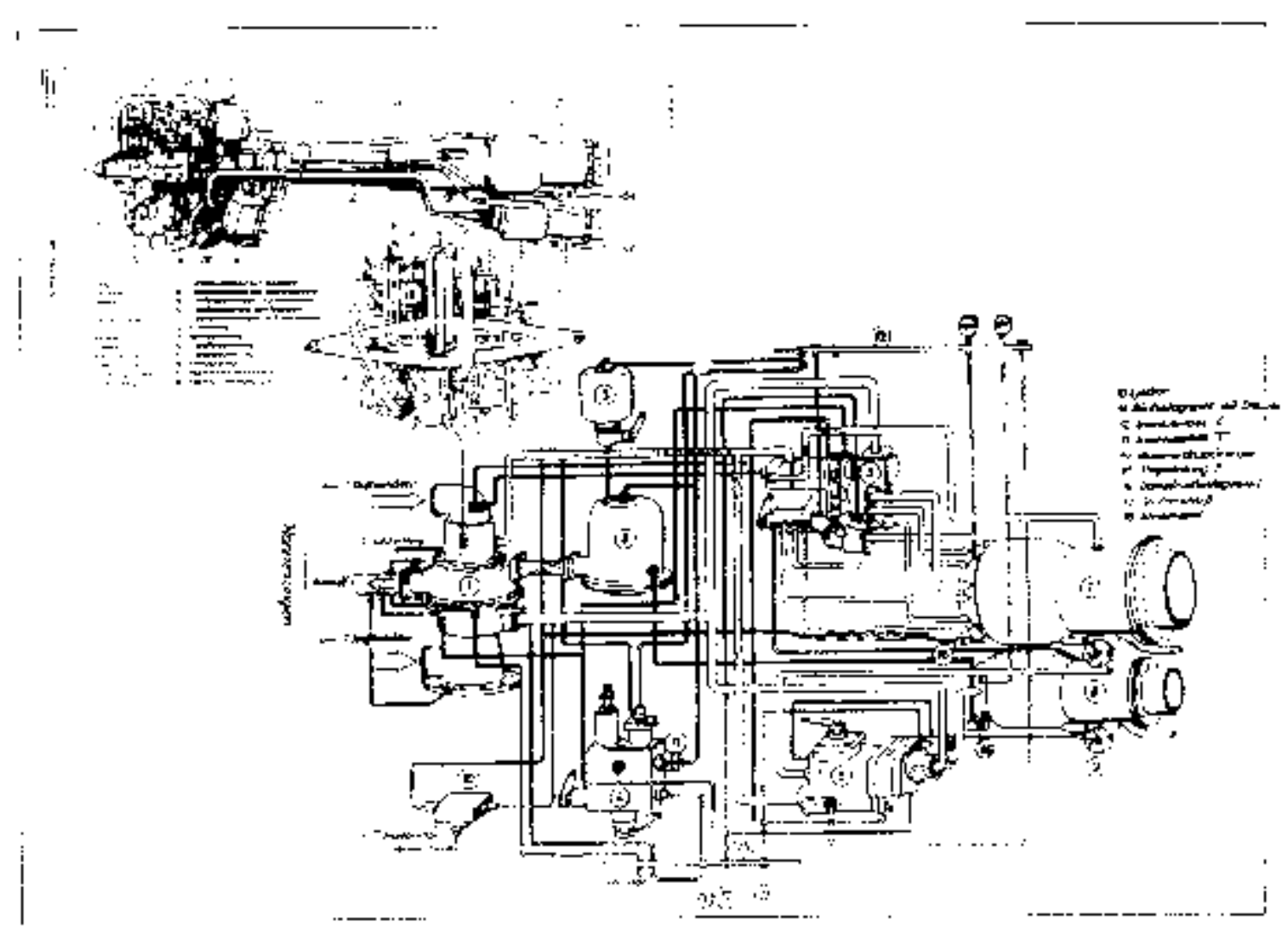

Fig. 8. The Walter 109-509C was the ultimate manned aircraft engine produced, and with separately throttled chambers with thrusts to $2000 \mathrm{~kg}$ (4,400lbs), and $200 \mathrm{~kg}$ (440lbs), was to power the second generation interceptor type Me 263/Junkers 248. The small chamber fulfilled cruise requirements, thus increasing versatility. The full thrust potential was at twice that of contemporary turbojet engines at low altitudes, and at the order of six times at altitude. Diminution of air density favoured aircraft drag reduction whilst reducing turbojet performance. Courtesy, Department of Documents, Imperial War Museum

In Germany prior to the collapse, final aircraft and engine development included the intent to provide a degree of cruise capability for the $M e 163$ by the provision of a supplementary rocket chamber maintaining high pressure ratio for efficiency, rather than by simply throttling the main chamber. This flew experimentally as the 109509B-l in a Me $163 \mathrm{~b}$ in July 1944 and was intended to pave the way for the Me $263 /$ Junkers 248 , to be powered by an increased thrust variant as the 109-509C at $2000 \mathrm{~kg}$ (4400 lbs.) and $200 \mathrm{~kg}$ (400 lbs.) thrust. Whilst bench tested initially in August 1944 it was not flown. The aircraft prepared for flight at the end of hostilities would have introduced a new practice in operation by alternating powered and gliding flight from altitude to extend range, and also allow an element of powered approach to avoid low level interception on return from its altitude mission.

Fig. 9. Aircraft rocket drives summarised in a comprehensive July 1945 Report. Allied Combined Intelligence Objectives Sub Committee. 'Rocket Power Plants Designed and Constructed by Walter Werke Kiel By Lieut. R. C. Stiff. USNR. Designations vary in the literature between the 'R. series of the Walter Works, and the 109-509 and 501 series of the RLM, German Air Ministry Propellant codes. Oxidants as T-stoff,, substance, hydrogen peroxide, or SV substance, nitric acid with $10 \%$ sulphuric acid in later missile production rounds. Catalysts as Z substance, aqueous solution of calcium or sodium permanganate, or B substance, hydrazine hydrate. Combined fuel and catalyst. C substance, 57\% methyl alcohol, 30\% hydrazine hydrate with water and potassium cuprocyanide- Courtesy, Department of Documents, Imperial War Museum 
A final 'Twilight of the Gods' project, along with other single seat Walter powered rocket Interceptors, was the Bachem $\mathrm{Ba}$ 394B Natter considered as a manned flack rocket and intended to be fired vertically to altitude and then to attack as an aircraft firing multiple rocket missiles. A batch of 12 was initiated, powered by a simplified Walter 109-509 AZ engine, but with the death of a pilot on the first flight trial consequent on booster rocket failure, the programme was terminated in the final months of defeat.

From April 1945 operation of the Me 163 ceased. No record exists of Allied shipping loss related to combat deployment of the XVII submarines. With the intensity of allied bombing, construction of the XXVI Atlantic Submarine was never completed.

\section{CHART 1}

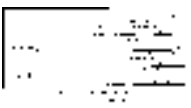

Hydrogen Peroxide, Walter and Germany. Within a 10 y ear time span peroxide power technology evolved from invention to production and the application of power plants across the diverse fields of land, sea, and air requirements.

\section{PEROXIDE POWER THROUGH THE COLD WAR ERA}

Following the end of the 1939- 1945 War the international tension of the Cold War took its place, and in the quarter century to the early 1970s peroxide power continued in its military applications with Britain a prime exponent of its continued development.

The intelligence services of the various Allied powers surveyed the surviving equipment and facilities and interrogated key technical personnel. At the end of the war, some two hundred Me 163 interceptors had been built and of the order of twenty of these were acquired for examination and proving, with most still in museums and the RAF returning one to Germany in 1988. Of the submarines, seven of the Type XVII were accounted for and U1407 of the Blohm and Voss boats operated in trials with the Royal Navy until 1950 as HMS Meteorite, confirming the attainment at 20 knots.

$U 1406$ went to the US Navy although the class was less directly applicable to their requirements. Trials appeared minimal, subsequent emphasis being in paving the way in hydrodynamics and turbine propulsion to the possibility of high speed with nuclear power.

The intended Atlantic Type XXVIW for which drawings had been completed had advanced in its construction until the intensive bombing of the Blohm and Voss yard and in June 1945 the British Commission was considering with Dr. Karl Fischer, their construction director, a programme for the construction of ten of the Class. Political policy however ran counter to this and the yard's facilities were destroyed. In 1946 one of the first project designs for a nuclear submarine in the USA was based on that 
of the Type XXVIW with substitution of a sodium graphite reactor for the peroxide generation arrangement.

In Britain an Admiralty Experimental Station was established at Welwyn to develop propulsion using hydrogen peroxide, as was an Admiralty Development Establishment in the Vickers Armstrong Works at Barrow-in-Furnace (ADEP) to research propulsion, both peroxide and nuclear. Dr. Forsyth, Head of the Vickers team, was in charge and he was joined in January 1946 by a group of former Walter Works key personnel under Hellmuth Walter himself. This paralleled the arrangement by which Professor Wernher von Braun, General Dornberger and their colleagues initiated their post-war careers in the USA with the Army Guided Missile Centre, as did Heinrich Gruenow the former Chief of the Peenemunde Experimental Shop in Moscow.

Walter worked for three years with the Vickers group but reports suggest that no close integration between teams was achieved as between ex-enemies in post-war Britain. This was exacerbated by salary taxation problems depressing comparisons as against the rewards gained in Russia and the USA. A related absorption of German personnel to the Westcott rocket work in Britain, inclusive of Walter Riedel the former chief designer at Peenemunde, was over a longer period an evident success.

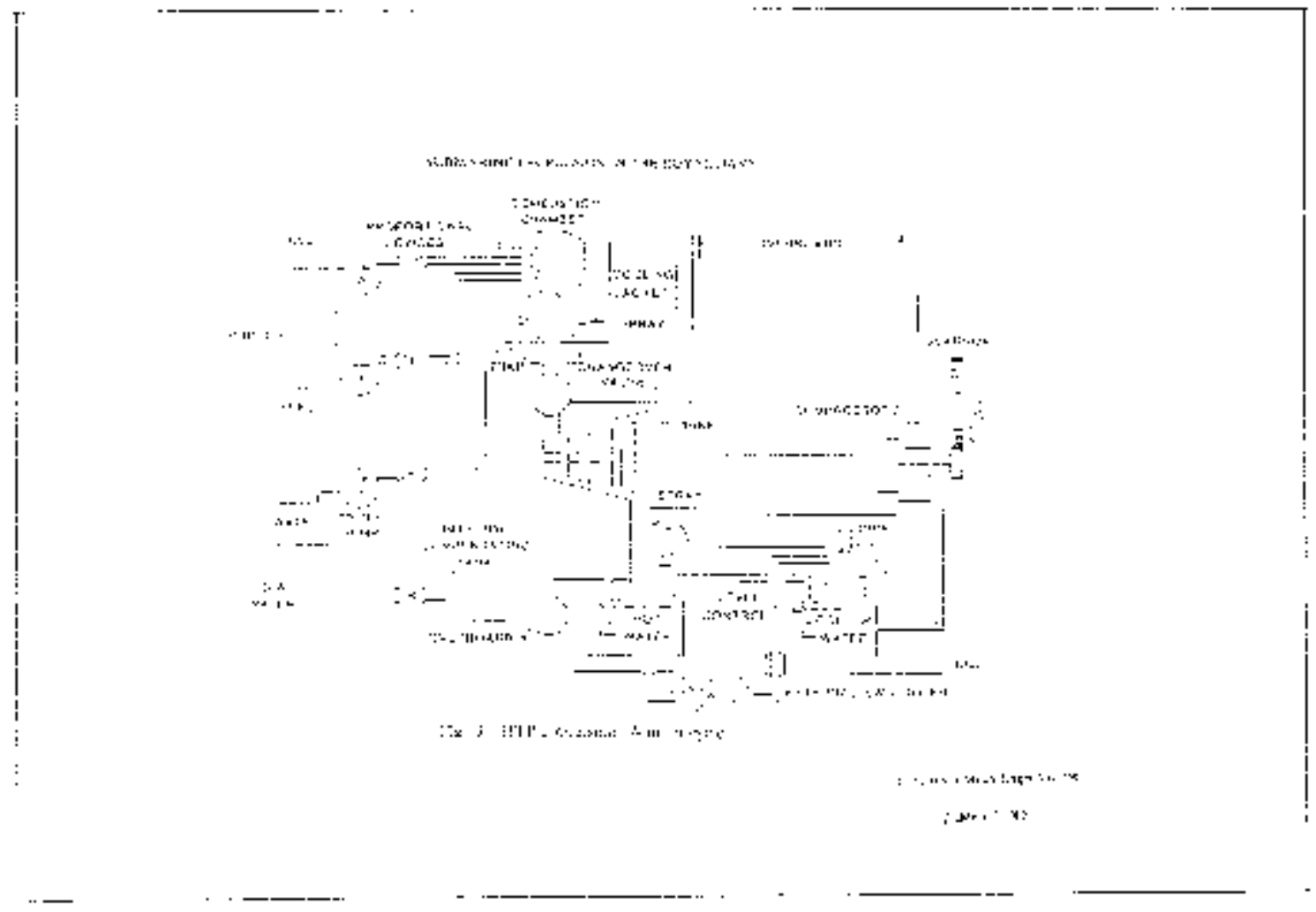

Fig. 10. Hydrogen Peroxide drive of the Royal Navy 'Excalibur' Class Submarines of the late 1950s. This carried to completion the Walter intent with regard to Submarine propulsion in derivation from the Type XXVI U Boat type, inclusive of combined jet and surface condensing with wakeless overboard discharge. Courtesy, Institution of Mechanical Engineers

The outcome of the work at Vickers was the operation from 1956 of HMS Explorer and from 1958 HMS Excalibur to designs evolved from the U Boat Type XXVIW as 
discussed ten years earlier. ${ }^{16}$ Other work was also pursued reverting to adaptation of diesel submarine propulsion with a modified cycle of fuel rich compression and ignition initiated by peroxide injection. With regard to the torpedo, adaptation of the British Mk 8 to a Mk 12 'Fancy' peroxide standard, on the model of the German 'Steinbut' piston engined unit, related to a major accident with the Submarine HMS Sidon as she prepared to go to sea on firing trials on 16 June 1955. Thirteen lives were lost with the explosion of the peroxide torpedo and she sank alongside the depot ship Maidstone. ${ }^{17}$

Whilst other Naval peroxide work has continued internationally from the 1960s, with the nuclear powered USS Nautilus at sea from 1955 major subsequent submarine development has concentrated on these types. Sweden has been most open with regard to its use of peroxide driven torpedoes with the FFV TP 61 in service since 1970 and the TP 617 from 1984, with development using a combination of peroxide and alcohol/diesel fuel with water injection and partial recycling of exhaust gases.

Russia pursued the German work on submarines generally with an apparently low key application of peroxide to a class described pejoratively as, 'cigarette lighters' in similar spirit to the British nickname of 'Exploder' for HMS Explorer. Rocket aircraft propulsion technology was developed with enthusiasm. The Me 163 was flown backed by a 'S' variant two seater for training purposes. A modified version of the $M e$ 263 was flown as the Mikoyan 1-270 in 1947 with a T tail enhancing high speed stability. Variants of the Walter engine were developed by L. S. Dushkin, initially of the Walter 109-509C with an upper cruise chamber, and reference is also made to supersonic flight attempts in May 1947 by a prone piloted variant with a twin 109509B engine although evidently drag limited speed to Mach 0.93. In 1955, whilst in the interim nitric acid oxidant had been favoured in airborne applications in compliance with former Russian practice, a MiG 19 variant flew with a hybrid boost engine using a peroxide turbopump with nitric acid main propellant, followed in 1957 with a variant with a variable thrust peroxide engine by D. D. Sevruk. This was in response to the British pursuit of the mixed power concept. ${ }^{18}$

In both the Russian and American development work from the V2/A4 through the series to the first attainment of sub orbital space flight the engines retained peroxide driven turbo pumps, as did the $X 15$ Aircraft. ${ }^{19}$ With the 'Mercury' Project, the 18 attitude control 'thrusters' on the Mercury ${ }^{20}$ spacecraft also utilised peroxide, as did the Bell personal 'man flyer' rocket belt that continues to fascinate. ${ }^{21}$

Considering particularly British aviation, through to 1946, whilst attempting to adjust to peacetime, consideration was given to the information and equipment emanating from Germany. In 1946 came Churchill's Iron Curtain speech. The Ministry of Supply (MOS) formed the Guided Projectile Establishment under W. P. Cooke at Westcott, Bucks, and the Rocket Propulsion Group under A. D. Baxter at RAE, Farnborough. Work commenced in applying the German technology, with the Halstead Experimental Centre of the MOS monitoring commercial exploitation. ${ }^{22}$

A related industrial activity was the initiation of project studies by F. B. Halford, Engineering Director of the newly formed de Havilland Engine Company of the DH Aircraft Group, to determine the business potential for rocket engines in aircraft engine manufacture, to follow up the success of their work on the turbojet aspect of 
jet propulsion. A. V Cleaver and W N. Neat of the Propeller Company, specialists in that field and established as members of the British Interplanetary Society, were recruited to form the Special Project This was to pursue the internationally perceived practice of harnessing enthusiasm to rocketry. ${ }^{23}$

Practical work was initiated as a private venture activity by the DH Company and commenced in 1947 by borrowing, from the MOS, Walter 109-501 ATO units; it then undertook a series of eight assisted take-offs with the Lancastrian aircraft utilised for flight testing the new DH Ghost jet engine, which would later power the DH Comet airliner. Interested and influential persons were given the opportunity to experience the integrated combination of piston, turbojet and rocket propulsion. This early association with a Walter unit seems to have established a link whereby subsequent DH engine work appeared to extend the Walter initiative. ${ }^{24}$

In 1948 occurred an interesting although different conjunction of activities. The $D H$ 108 aircraft to Spec E.18/45 as a tailless derivative of the DH Vampire jet fighter, had flown from 1946, applying the technology pioneered in the Me 163. It had a thin symmetrical section swept wing with elevons and swept fin and rudder. On 9 September 1948 it was flown by John Derry in a vertical full power dive from 45,000 $\mathrm{ft}$ to supersonic speed. The former intended British contender for flight at supersonic speed, the Miles M52, had been cancelled in 1946 due to uncertainty concerning its turbojet engine thrust potential and the risks of manned flight. A half scale model was then built by Messrs. Vickers with a $362 \mathrm{~kg}$ (800 lbs.) thrust hydrogen peroxide 'hot' motor evolved at Westcott with characteristics drawn from the Walter RI 2031209 ATO unit. This initiated the Beta and the subsequent Gamma Ministry inspired engines. In October 1948 the Vickers Transonic model flew at $930 \mathrm{mph}$ in level flight at $35,000 \mathrm{ft}^{25}$

The DH Engine Co. continued to pursue a .strong initiative and, in concentrating rocket effort on hydrogen peroxide, they enjoyed MOS support for contractual and research activities. Thus they reflected development in the field in the period to the 1960 s. $^{26-29}$

The DH Comet airliner, applying to civil operation the benefit of jet propulsion, was assessed as requiring an ATO unit at hot and high locations. The Sprite DSpr.l engine was designed as a lightweight fit to provide 2265kg (5000 lbs.) thrust for 15 seconds at a dry weight of 158kg (350 lbs.). It operated 'cold' on Walter principles with liquid catalyst. Flight trials were undertaken from May 1951 with the Comet prototype. With a total of 30 assisted take-offs, it presented a near routine image for civil operation in the spirit of the age.

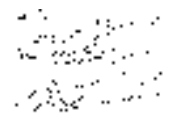

Fig. 11. de Havilland 'Sprite' of 1949 as flown as part of the concept of the first jet propelled 'Comet' airliner in satisfying for hot and high take-off requirements on Empire routes. Contrasted with the 'Super Sprite' unit, the first type tested unit for assisted take-off of the RAF 'V' bomber force 'Valiants'. Illustrates the transition between direct adaptation of the German technology with a 'cold' unit and the latter 'hot' unit with plated silver catalyst gauzes. Courtesy RRHT 
A technology update then took place with the proving of silver plated nickel gauze packs as catalysts with the establishment of optimum loadings and flows. This practice was replicated in all future applications with the catalyst no longer consumed. In April 1952 the DSpr.2 proved this modification impressively in Comet demonstration with clean exhaust. The next stage was pursued with the Super Sprite DSpr.4 following the ATO development precedent with 'hot' operation but now enhanced in simplicity by ability to inject kerosene fuel once chamber pressure was established by the catalysed peroxide flow. The units, flight approved in August 1953, reverted to the practice of being parachuted after firing for routine re-use in service operations with the Vickers Valiant V bomber. The bulk of the 166 units manufactured came from a production line away from the development shop and were supported by the Service Department in with piston and turbojet engines. It was the first rocket engine to gain formal type approval. ${ }^{30}$

In 1952 rig testing commenced with the Spectre DSpe.l rocket interceptor engine in line of succession to the Walter 109-509 engine. The aircraft industry had no positive precedent for an engine which would gain in thrust with altitude and market response suggested maximum thrust requirements between $900 \mathrm{~kg}$ (2000lbs.) and 6800kg $(15,000 \mathrm{lbs}$.) thrust. The design was based on a variable thrust which could be throttled between 3620kg (8000lbs.) to $900 \mathrm{~kg}$ (2000lbs.). Design philosophy was matched to the mixed power concept of an aircraft having both a turbojet and rocket engine for maximum operational flexibility. ${ }^{31}$

Technological innovation embraced the Barske high speed open impeller centrifugal pumps, ${ }^{32}$ as formerly researched in the Walter organisation, regenerative peroxide chamber cooling with pump stages upstream and downstream, gauze catalyst packs, low loss internal flow turbine and the use of straight kerosene fuel. The aircraft tanks were to be pressurised to suppress pump cavitation problems.

Engine development then proceeded logically, with one major redesign. ${ }^{33}$ It went through rig tests commencing in 1953, bench tests from mid-1954, and testing in two Canberras. From flight approval in Autumn 1956, flight experience again posed altitude starvation problems. Clearance was given for flight in the prototype Saunders Roe SR 53 from May 1957, this was joined subsequently by a second aircraft.

In October 1957 a contract was announced for a more advanced version of the aircraft as the SR 177 to utilise a revised design Spectre DSpe.5 engine together with a reheated supersonic capability 14,000 lb. thrust DH Gyron Junior PS 50 turbojet engine, thus meeting a full mixed power aircraft concept. In conjunction with the new engine, development had been undertaken with two major ancillaries, a peroxide starter for the gas turbine and a peroxide auxiliary power unit. Virtually on the heels of the announcement of the contract came the notorious Sandys White Paper declaring, evidently much to the surprise of Russia, that all future combat would be undertaken by computer controlled missiles.

Development flying of the SR 53 continued through 39 flights operating to Mach 1.33, and to altitudes at 55,000 ft, as research and construction proceeded on the $S R 177$, the latter consequent on a potential order from the German Navy and other possible customers. Squadron Leader John Booth, Saunders Roe's Chief Test Pilot perpetuated the spirit of former rocket aircraft pilots and the technical teams in his dedication and 
overall involvement in engine development. Sadly he was killed on 15 June 1958 in an aborted take-off of the prototype $S R 53$ running into obstructions off the end of the runway. No cause was ascribed and no blame cast on the engine. No further flying was undertaken with the aircraft type and shortly afterwards the SR 177 project was terminated.

All the engine and ancillary unit developments proceeded in other applications, but following the disastrous White Paper which severed contracts for first line fighter power, DH business emphasis started to be re-directed to entry into the gas-turbine turboshaft market. An interesting guided missile orientated project from 1955 however was investigation of the air turbo-rocket principle utilising fuel rich combustion with peroxide of a hydrocarbon (C3H4, Propyne) as a power source, with combustion then completed with the air of the engine propulsive exhaust stream. The conventional Spectre DSpe.5 had been developed alongside a DSpe.4 ATO variant, the latter for the Avro Vulcan and HP Victor bombers, another programme subsequently cancelled after a single trial take-off of a Victor from the DH aerodrome at Hatfield. These two engines were then used in combination to power the development rounds of the Avro Blue Steel missile stand-off bomb, together with the peroxide APU, from its first flight in October 1959.

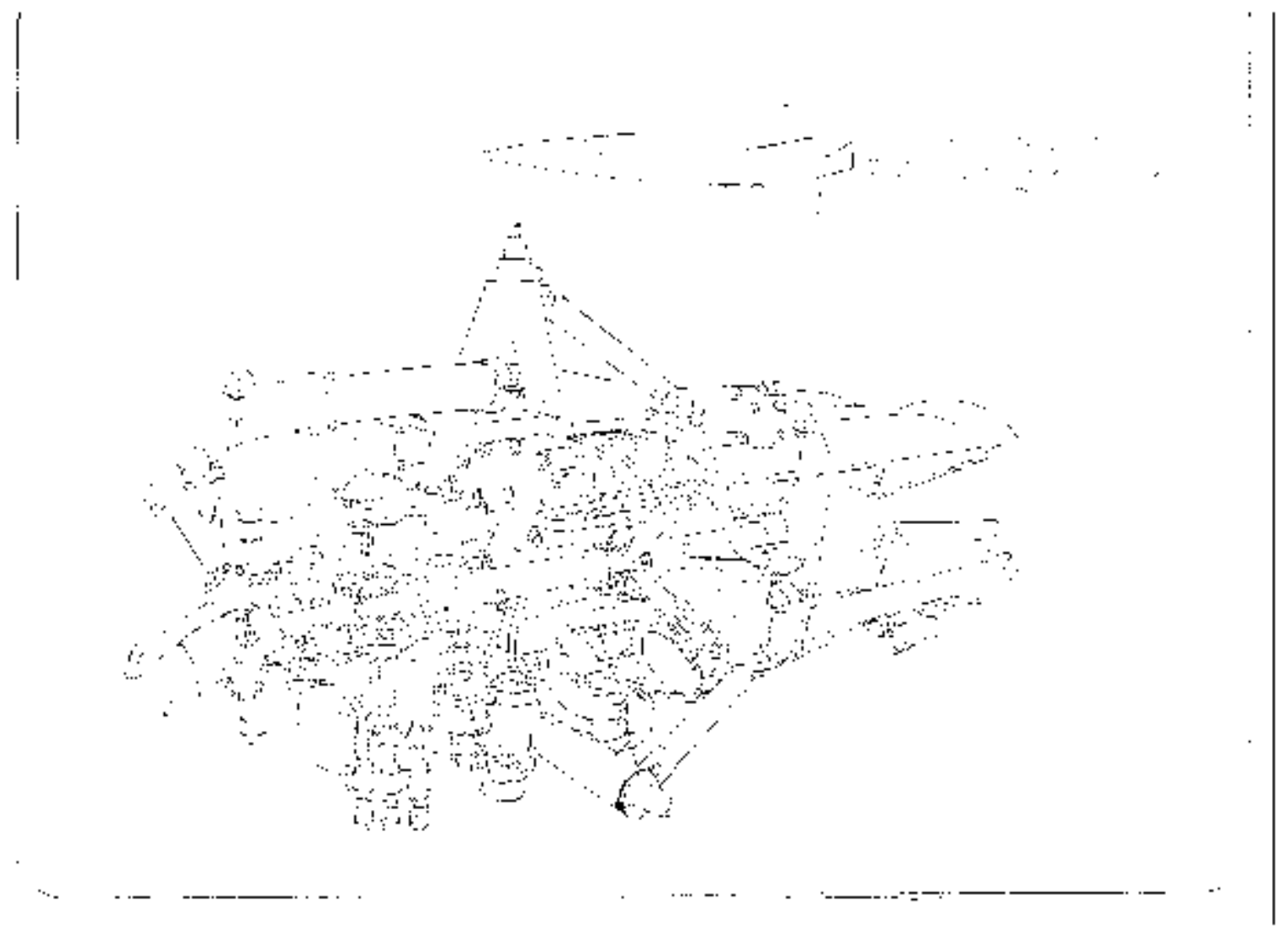

Fig. 12. de Havilland 'Spectre $1 V^{\prime}$ ' rocket motor. Established British post war type as derived and developed from the SR 53 Prototypes 'Spectre l' type. With 'Barske' type pumps, internal low loss turbine, silver gauze catalyst, etc. Design intent as 'Spectre V' for interceptor SR 177, and 'Spectre 1V' for 'V' bomber take off. Coupled units for early 'Blue Steel' proving rounds Courtesy, RRHT

In the early 1950s other established aircraft engine companies were brought into participation in peroxide work to obviate single source fears. Initially involvement 
was primarily by manufacturing and development contracts in support of the Ministry Beta and Gamma engines. In 1952 Napier were providing engines for missile trials in a line of development from Beta. In 1956 the Napier Scorpion engine commenced flight trials in a Canberra and in 1957 the aircraft with a twin unit established a world height record at 21,427 m, (70,300 ft). This was of course, on the eve of cancellation of manned aircraft programmes.

Whilst, prior to 1955. Armstrong Siddeley had concentrated on LOX oxidant engines, including the AS Snarler and Screamer, use of this oxidant in airframe type applications was now cancelled, together with the Avro 730 airframe in its competition with the SR 53 Armstrong Siddeley, soon rationalised into Bristol Siddeley and absorbing the former DH rocket and newly gained torpedo work now took up hydrogen peroxide.

It undertook development of the Gamma with a four, $1857 \mathrm{~kg}$ (4100 lb.) chamber gimballed unit for the Black Knight research rocket. This subsequently underwent a successful series of suborbital flights from 1958 with Gamma Mk 201 and 301 engines. In 1960 the $9060 \mathrm{~kg}$ (20,000 lb.) thrust BS Stentor peroxide engine was available for the Avro Blue Steel and entered service with Vulcan B2's of the RAF 617 Squadron in February 1963, continuing in service to 1971 as a Mach 1.6 missile.

From 1969 the Black Arrow two stage space vehicle programme with BS Gamma 301 engines was initiated and in October 1971, with the programme cancelled, achieved orbital flight, the only satellite launch vehicle to date to be powered with the peroxide oxidant.

\section{CHART 2}

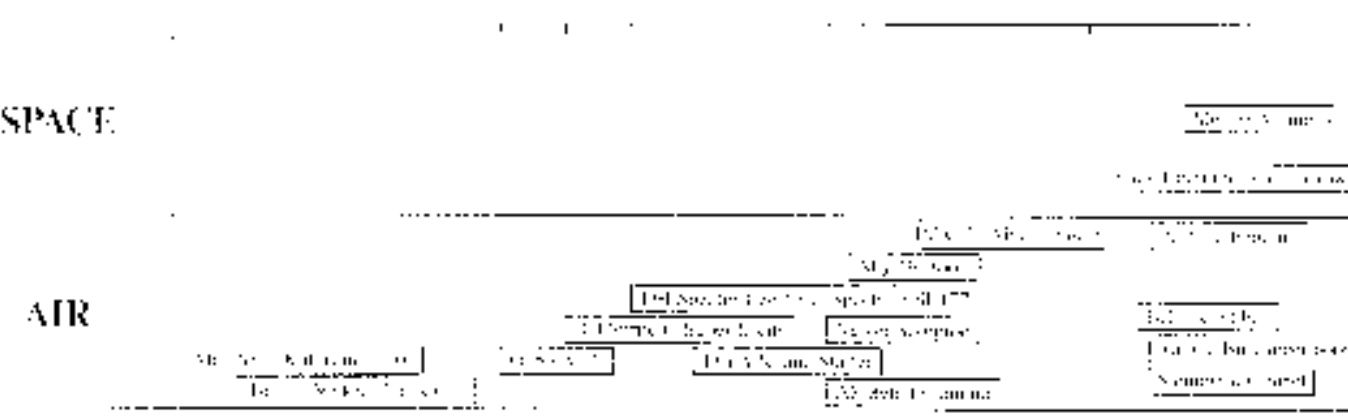

CRINAYCE
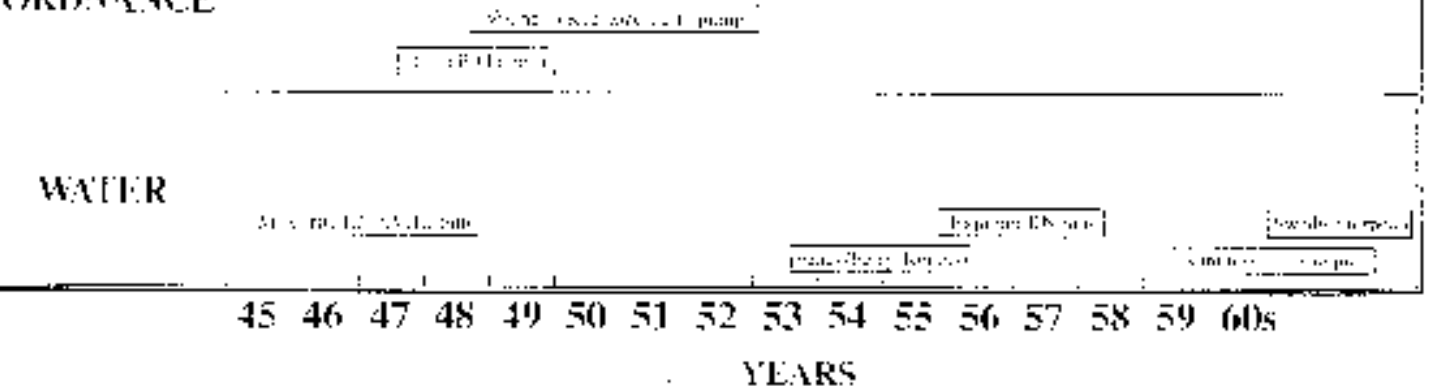

Hydrogen Peroxide - Post World War2 Initially the spoils of war to the victor nations and then evolving to a breadth of applications, inclusive of Space. 


\section{THE FUTURE?}

In Japan in 1992 the Toyota Company staged its employee 'Idea Expo', an annual competition of imagination, creativity and sheer good fun. One of the six award winning entries was the Breather.

Breather, like human beings, runs on oxygen. Unlike us, what it leaves behind is totally harmless to the environment. 'I perceived the idea of making a car that can run by clean gas,' said Kazuaki Okada at Toyota's assembly engineering division, 'when I was visiting a factory where many facilities were operated by air pressure'. But even before that, Okada harboured the idea as a result of a high school chemistry experiment which went awry. The vehicle is fuelled by hydrogen-peroxide (35\% proof solution) and emits oxygen. Hydrogen peroxide is added to a holding chamber in the rear of the vehicle. The switch of a valve allows the hydrogen-peroxide to enter a platinum converter.

The reaction which occurs yields water and a volume of oxygen 460 times the volume of the original solution. The oxygen which is produced becomes pressurised in the chamber and is used to operate an air motor which drives the rear wheels. The vehicle exhaust is water and oxygen-the products of the chemical reaction. Maximum speed is $10 \mathrm{~km} / \mathrm{hr}$, with $0.26 \mathrm{hp}$.

Toyota Press Information: October 14, 1992.

I choose this statement in conclusion as reflecting the spirit of enthusiasm with which such endeavours in the application of new technology commence. It suggests a situation full circle to that of 1930 when attention was first turned to thoughts of an alternative power potential in the use of hydrogen peroxide. Doubtless military applications continue. In future as problems mount with fossil fuels, might one visualise application at some optimum strength to vehicular propulsion offering zero or low level contamination alongside such potential energy sources as the fuel 11, etc?

\section{NOTES AND REFERENCES}

1. W S. Wood. Hydrogen Peroxide, Royal Institute of Chemistry. Lectures, Monographs and Reports. No. 2 (1954).

2. Wily Ley, Rockets. Missiles, and Space Travel. (Chapman \& Hall, 1952).

3. Henry. H. Suplee, The Gas Turbine, (Charles Griffin \& Co, 1910).

4. L. McKef, Hydrogen Peroxide for Propulsive Power. Production and Use by the Germans During World War 11, Trans IMarE, 1947-48, Vol. 59, pp. 1821.

5. Rüssler, The U-Boat: The evolution and technical history of German Submarines. Transl. by Harold Erenberg. (Arms and Armour Press. 1981).

6. National Advisory Committee for Aeronautics, Tech. Memo. No. 1 170Report on Rocket Power Plants based on T-Substance. (NACA Comment: hydrogen peroxide). By Hellmuth Walter. From the German. 'Bericht über die R-Triebwerke auf Grundlage des T-Stoffes.' R-Antribe, Schr d. D. Akad. Luftfahriforschung, Heft 1071, Nr. 82, 1943, pp- 63-89.

7. Ernst Heinkel, He 1000- (Hutchinson, 1956).

8. Emil von Kruska \& Eberhard Rüssler, Walker- U-Boote (J. F. Lehmanns Verlag, München, 1969).

9. T Lenton, Navies of the Second World War, German Submarines 2, (Macdonald, 1965).

10. European Rocketry after World War 1, Article on 'History of Astronautics'. R. Dornberger. Realities of Space Travel, Ed. L. J. Carter, (Putnam, 1957). 
11. 'The Mechanism of the German Rocket Bomb (V2).' Informal Discussion on Friday, 12 October 1945, introduced by W. G. A. Perring. Proc. IMech.Engrs., vol. 154 ( 1946).

12. 'Walter-Werke, Kiel.' Reported by Capt. C. L. Barham, M. O. S., F/Lt. R. Simard, M.A.P., CIOS Target No. 5/3 \& 5/69. Jet Propulsion. Combined Intelligence Objectives sub-Committee, G-2 Division, SHAEF (Rear) APO 413.

13. Wolfgang Spate, Top Secret Bird, The Luftwaffe's Me 163 Comet, (Pictorial Histories Publishing Company. Missoula, Montana. 1989).

14. HEC 10670 (BIOS/HEC 103B. Class No: 629.13.035.4 (43) Walter. R.A.E. Tech. Note. Gas.12. March, 1946. Information on Walter Rocket Propulsion Units developed from 1936 to 1945.

15. Rocket Power Plants Designed and Constructed by Walter Werke, Kiel. Reported by Lieut. R. C. Stiff, USNR, NavTevcMisEu, July 1945. CIOS Target Nos. 4/4ga, 13 \& 5/69 Rocket and Rocket Fuels, Jet Propulsion. Combined Intelligence Objectives Sub-Committee G-2 Division, SHAEF (Rear) APO 413.

16. T Horlick, (Sir), 'Submarine Propulsion in the Royal Navy,' IMechEngrs. Proc. Vol. 196 No. 7 (1982).

17. G. Carter, 'The loss of the Submarine HMS Sidon, 16 June 1955, Warship World, Summer, 1988.

18. A. Belyakov \& J Marmain. MiG, 50 Years of Secret Aircraft Design. (Airlife Publishing, 1994).

19. 'X-15, The World's Fastest and Highest Flying Aeroplane,' Flight, 8 May 1959.

20. 'The Mercury Spacecraft in Detail,' Flight International, 8 February 1962.

21. 'Personal Rocket Lift Device, Bell Aerosystems,' US Patent 3,021,095. 1962.

22. D. Baxter, , Aircraft Rocket Motors, With Special reference to German Developments with Hydrogen Peroxide,' Aircraft Engineering, August 1947.

23. Barker, T.R.F Nonweiter \& R.Smelt, Jets and Rockets. (Chapman \& Hall Ltd, 1959).

24. P Stokes, From Gipsy to Gem with Diversions 1926-1986, (Rolls Royce Heritage Trust, 1987).

25. V. Cleaver, 'Rockets and Assisted Take-Off, Journal, Royal Aeronautical Society, Feb. 1951.

26. Burnet. Three Centuries to Concorde, (Mechanical Engineering Publications. 1979).

27. 'Progress with Rocket Engines,' The Aeroplane, 6 August 1954- Inclusive of ongoing comparison of hydrogen peroxide, liquid oxygen, and nitric acid as oxidants, application perspective DH Super Sprite and AS Snarler.

28. J. A. Williams, 'Properties of Hydrogen Peroxide, Laporte Chemicals Ltd. The Aeroplane, 6 August 1954.

29. 'Enterprise in Rocketry Activity at De Havilland Engine Co.' The Aeroplane, 4 March 1955.

30. Hydrogen Peroxide as a Source of Energy. (de Havilland Engine Co. 1957).

31. 'More About the Super Sprite,' The Aeroplane 29 July 1955, 'Super Sprite. The First British Production Type A.T.O. Rocket Motor. Flight. 5 August 1955.

32. W. N. Neat, 'Development of the Spectre, Lecture to Royal Aeronautical Society. 4 November 1958. Reported Flight 14 Nov. 1958. 
33. U. M. Barske, 'Development of Some Unconventional Centrifugal Pumps' Proc. IMech Engrs, Vol. 174.No. 11, 1960.

34. L. S. Snell. 'The Design and Evolution of an Aircraft Rocket Engine,' Institution of Engineers, 22 November 1963.

Reference was also made to the following magazine articles in preparing this paper.' 'Missiles and Spaceflight, Blue Steel in Action,' Flight, 11 March 1960.

'Napier Rocket Engines. The English Electric Journal, June 1957

S. Allen, 'Rockets for Aircraft Propulsion,' The Aeroplane, 7 Dec. 1951

'The Armstrong Siddeley Screamer, a Powerful Rocket Motor from Coventry; Flight. 27 July 1956.

J. H. Stevens, 'Black Knight, An Inspection and Some Deductions. Flight, 17 Oct. 1958.

'Gamma, Details disclosed of Armstrong Siddeley's Four-rocket Powerplant for Black Knight, Flight, Jan. 1959.

'Black Knight', Flight International, 23 July 1964.

'Rocket Engines for Piloted Aircraft,' Bristol Siddeley Magazine, 1960.

'Rocket Engines,' Broadsheet, Bristol Siddeley Supply the Power, August 1966.

\section{ACKNOWLEDGEMENTS}

In the broad coverage undertaken, prime sources have been listed under the notes and references. To access this information, and in pursuing a long-term interest, I have been assisted by Library and Museum staff in London at the Institution of Mechanical Engineers, the Royal Aeronautical Society, the Institution of Marine Engineers, the National Maritime Museum, and at the RAF Museum. Also at the Royal Navy Submarine Museum and the Archive at Gosport, Hants. Interest arose consequent on employment in the field with the de Havilland Engine company, subsequently integrated into Rolls Royce plc, and the Rolls Royce Heritage Trust perpetuates the desire to research and record this past. Bob Tanner of the Trust produced for me a key illustration.

I would make particular acknowledgement for help received from the Chairman of the Editorial Board and Editor of Transactions, Mr. L. R. Day, MSc, for all his help and guidance in correcting and shaping an engineer's text into worthwhile form.

\section{DISCUSSION AND CORRESPONDENCE}

Mr. C. A. Comyns-Carr (Member) writes: proposal for an aero engine called the turborocket was the subject of a design study by Rolls Royce in 1956. It was actually a development of the ramjet engine in which thrust is dependent on the forward speed 
of the aircraft to ram the air into a diverging duct where static pressure increases and fuel is injected and burned. Although efficient at speeds above Mach 2, with no compressor or turbine it cannot provide thrust for take-off.

To overcome this limitation the turbo-rocket had a single stage supersonic compressor ahead of the combustion chamber. The compressor was direct coupled to a turbine driven by gas from a rocket chamber burning HTP and kerosene. The turbine exhaust discharged into the main air stream ahead of the fuel injectors where most of the fuel was burned. With this arrangement the engine could operate either on "rocket" power for take-off, or as a pure ramjet with rocket power turned off, or as a ramjet augmented by the turbine-driven compressor for combat.

The rocket chamber, the turbine and all the engine auxiliaries were contained within the centre body formed by the inner wall of the engine annulus.

Other relevant correspondence was as follows.

The Author writes: In preparing the paper contact had been established with the company Walterwerk Kiel GmbH \& Co. KG, the succeeding company of H. Walter $\mathrm{KG}$ at Kiel in Germany which had originated the work. In his letter the General Manager of the company advised that activities were located in the former Walter facilities built in 1939, and that the company was refounded by Professor Hellmuth Walter and some of his former co-workers in 1956

After a business period of research and development in the field of air-independent power plants and rocket drives we changed our activities 20 years ago. Now we are one of the leading manufacturers and suppliers of wafer baking equipment which is delivered around the world. Besides this we operate an engineering division for the development and construction of mainly naval equipment and machinery used in the shipbuilding industry.

The letter added that they were glad to hear that the Society is interested in the history of the works, whilst advising that in Kiel cultivation of history only embraces two locations where Hellmuth Walter's developments are mentioned. These are the Schiffahrtsmuseum Kiel, and the Marine Museum (Ehrenmal Laboe). There is at present no technical association in Kiel pursuing the subject, whilst the firm still honours the name of the founder and is proud of its contribution to technology.

In correspondence with the German author specialising in the history of the U Boat, Eberhard Roessler, from Berlin, he proffered appreciation of the paper and particular interest in the dates concerning work with HTP in England. He was able to suggest additions to the bibliography on the subject with the following.

Spasky and Semyonov, 'Project 617. the Soviet Whale', United States Naval Institute, 11112, 1994.

Roessler and Koehl 'Uboottyp XVII-Walter-Uboote-', Bernard \& Graefe Verlag, Bonn, 1995.

Roessler, 'Die großen Walter-Uboote', Bernard \& Graefe Verlag, Bonn, 1998 (not edited yet).

Additionally he advises that: 
'It might be of interest for you to know that there had been a project in 1980 or later supported by the ministry of science of the Federal Republic of Germany with the idea to produce HTP with the help of solar energy at the African coast and to bring it to Europe via big HTP-tankships. There electric energy should be produced by HTP and Walter-turbines without CO emission. For this project no investor was found so far. -

\section{AUTHOR' S COMMENTS}

The brief informal discussion after presentation of the paper and the subsequent correspondence had been of great interest in complementing the paper and indicating further development of the technology.

John Harlow the Programme Manager Special Projects of Royal Ordnance plc at Westcott, Aylesbury was in attendance and, in expressing his interest, confirmed that the use of HTP continued as an option in rocket investigations.

With Mr. Robin Comyns-Carr's contribution, the work he describes was complementary, at least in time, to the work briefly related at DH's in the published paper concerning the combustion experiments with peroxide and propyne.

The Air-Turbo rocket proposal, apart from its own inherent interests, demonstrates the aspect of the potential for ongoing interest and application in the military and aerospace field. A version, with two stage geared fan, continues to be featured in the Rolls Royce publication 'The Jet Engine', probably the prime world wide field training guide on its subject. It is included to intrigue and broaden thinking on future potential along with the TurbolRam jet engine for the field of ultra high speeds at altitude.

The power station concept advised by Herr Roessler reflects a relevant aspect of the lateral thinking evident in the 1980's on the last occasion when a World fuel crisis threatened non-availability of hydrocarbon fossil fuels. This, together with increased ecological concerns, makes further consideration of the solar powered PeroxideRankine cycle power station an intriguing prospect as an extrapolation of the history considered in this particular study. 